NBER WORKING PAPER SERIES

\title{
SUPPLEMENTAL SECURITY INCOME AND CHILD OUTCOMES: EVIDENCE FROM BIRTH WEIGHT ELIGIBILITY CUTOFFS
}

\author{
Melanie Guldi \\ Amelia Hawkins \\ Jeffrey Hemmeter \\ Lucie Schmidt \\ Working Paper 24913 \\ http://www.nber.org/papers/w24913 \\ NATIONAL BUREAU OF ECONOMIC RESEARCH \\ 1050 Massachusetts Avenue \\ Cambridge, MA 02138 \\ August 2018
}

The views expressed by the authors do not necessarily represent the views of the Social Security Administration, the National Science Foundation, or the National Bureau of Economic Research. We owe special thanks to Bevin Ashenmiller, Susan Averett, Martha Bailey, Alan Barreca, John Bound, Matias Cattaneo, Karen Conway, Ken Couch, Paul Davies, Stefanie Fischer, Jason Fletcher, Daniel Grossman, Sarah Hamersma, John Jones, Ilyana Kuziemko, Mike Levere, Sarah Miller, Stephanie Rennane, Stephen Ross, Jeff Smith, Michael Stephens, Alexander Strand, and Rebecca Vallas for valuable feedback. We would also like to thank seminar and conference participants at Amherst College, Miami University, Occidental College, Stony Brook University, the University of Connecticut, the University of Kansas, the University of Michigan, the University of New Hampshire, Vanderbilt University, Vassar College, Williams College, the New England Study Group at the Boston Federal Reserve Bank, the Boston University/Harvard/MIT joint Health Economics seminar, the 2016 Eastern Economic Association Annual Meeting, the 2016 Midwest Economic Association Annual Meeting, the 2016 Western Economic Association Meeting, the 2016 Southern Economic Association Meeting, the 2016 National Tax Association Meeting, the 2016 American Society of Health Economists Meeting, the 2016 APPAM International and Fall Conferences, the 2016 NBER Summer Institute, and the 2016 Southeastern Health Economics Study Group Conference. Any remaining errors are our own. Amelia Hawkins gratefully acknowledges support from the National Science Foundation Graduate Research Fellowship under grant number DGE \#1256260, a NICHD training grant to the Population Studies Center at the University of Michigan under grant number T32HD007339 and NBER's pre-doctoral fellowship program.

NBER working papers are circulated for discussion and comment purposes. They have not been peer-reviewed or been subject to the review by the NBER Board of Directors that accompanies official NBER publications.

(C) 2018 by Melanie Guldi, Amelia Hawkins, Jeffrey Hemmeter, and Lucie Schmidt. All rights reserved. Short sections of text, not to exceed two paragraphs, may be quoted without explicit permission provided that full credit, including $\odot$ notice, is given to the source. 
Supplemental Security Income and Child Outcomes: Evidence from Birth Weight Eligibility Cutoffs

Melanie Guldi, Amelia Hawkins, Jeffrey Hemmeter, and Lucie Schmidt

NBER Working Paper No. 24913

August 2018

JEL No. H51,H53,I38,J21

\begin{abstract}
Low birth weight infants born to mothers with low educational attainment have a double hurdle to overcome in the production of human capital. We examine whether income transfers in the form of Supplemental Security Income (SSI) payments for children with disabilities can help close the gap in outcomes due to this initial health and environmental disadvantage. We exploit a discontinuity in SSI eligibility at 1200 grams and use a regression discontinuity approach to produce causal estimates of the effects of SSI eligibility. We find that eligibility increases disability benefit participation, improves child outcomes and parenting behaviors, and shifts maternal labor supply from full to part time.

Melanie Guldi

Department of Economics

University of Central Florida

4336 Scorpius Street

Orlando, FL 32816-1400

mguldi@bus.ucf.edu

Amelia Hawkins

Department of Economics

University of Michigan

611 Tappan St.

Ann Arbor, MI 48109

aaehawki@umich.edu

Jeffrey Hemmeter

Office of Research, Demonstration, and Employment

Social Security Administration

4303 Annex Bldg

6401 Security Blvd

Baltimore, MD 21235

jeffrey.hemmeter@ssa.gov

Lucie Schmidt

Department of Economics

Williams College

201 Schapiro Hall

Williamstown, MA 01267

and NBER

1schmidt@williams.edu
\end{abstract}

An online appendix is available at http://www.nber.org/data-appendix/w24913 


\section{Introduction}

Individuals born to mothers of lower socio-economic status (SES) experience worse outcomes than children born to mothers with greater resources. These differences across SES are immediate, persist as children age, and have been widening over time (Currie, 2011; Kalil, Ryan, and Corey, 2012; Aizer and Currie, 2014; Currie and Rossin-Slater, 2015; Autor et al., 2016; Economic Report of the President, 2016, ch. 4). Low birth weight alone is also associated with diminished economic and health outcomes, though greater family resources mitigate the severity of low birth weight’s negative impact (Behrman and Rosenzweig, 2004; Black, Devereux, and Salvanes, 2007; Oreopolous et al., 2008; Aizer and Currie, 2014). Low birth weight infants born into low-SES families face a particularly steep uphill climb to achieve outcome equality. Fortunately, prior research has shown that both public and private investment can improve outcomes by alleviating credit constraints, improving access to health or education services, and reducing stress (Almond and Currie, 2011; Aizer, 2014; Akee et al., 2018; Currie and Rossin-Slater, 2015; Jones, Milligan, and Stabile, 2015; Aizer et al., 2016; Almond, Currie and Duque, 2017). In this paper we study a particularly vulnerable population—infants born at very low birth weights, below 1200 grams, to mothers with a high school degree or less. We explore whether public investment in these infants in the form of Supplemental Security Income (SSI) mitigates the detrimental impact of being born at a double disadvantage.

The SSI program provides means-tested income support to individuals with disabilities and the elderly in the United States. For children on SSI, cash payments make up 45\% of family income (Bailey and Hemmeter, 2015), and SSI reduces poverty among those families (Duggan and Kearney, 2007). Although only $4 \%$ of children under $200 \%$ of the federal poverty line receive SSI (Wittenburg et al., 2015), the public resources allocated to SSI are nontrivial; eleven 
states have more child SSI recipients than child Temporary Assistance to Needy Families (TANF) cash benefit recipients, and expenditures on child SSI exceed federal and state expenditures on child TANF cash benefits (Tambornino, Crouse, and Winston, 2015; Wittenburg et al., 2015). However, despite these expenditures on the program, little is known about the relationship between SSI payments and infant or early childhood outcomes.

To fill this research gap, we are the first researchers to exploit discontinuous changes in SSI eligibility at birth weight thresholds, the first to analyze the relationship between SSI received during infancy and child outcomes, and the first to estimate the relationship between child SSI program entry and parental employment. According to Social Security Administration (SSA) rules, children qualify for SSI based on extremely low birth weight if they either weigh less than 1200 grams at birth, or fall below cutoffs based on birth weight for gestational age (Social Security Administration, 2015). To estimate causal effects, we use a regression discontinuity (RD) approach to compare outcomes for infants born just under the 1200-gram SSI eligibility cutoffs to those outcomes for infants born just above the cutoff. ${ }^{4}$ We use the Early Childhood Longitudinal Birth Study (ECLS-B) to show that the likelihood of disability benefit receipt increases discontinuously at the 1200-gram cutoff, while other infant and family characteristics do not exhibit changes at this cutoff. Next, we estimate the relationship between SSI eligibility and several important outcomes including measures of health insurance coverage, child development, parenting behaviors, parental labor supply, and infant mortality using data from the ECLS-B, the Healthcare Cost and Utilization Project State Inpatient Database (HCUP-

${ }^{4}$ The 1200-gram cutoff is one of several used by the Social Security Administration. We discuss why we focus on this one in the Methodology section. 
SID), and the National Center for Health Statistics (NCHS) Birth Cohort Linked Birth-Infant Death Data file (BC-L). We find that SSI eligibility significantly improves parenting behaviors and child motor skill development. We also show that SSI eligibility reduces maternal labor supply on the intensive margin, a result consistent with reallocation of parental time towards child investments. Last, our results suggest that SSI eligibility for low birth weight infants increases Medicaid enrollment as a secondary payer, but does not affect infant mortality rates.

Our findings contribute to the growing body of evidence linking public investments in children to improved outcomes, and suggest that providing SSI to these doubly disadvantaged families improves parenting behaviors and children's development. These gains are most marked for children of the least educated parents -- parents who likely have the fewest private resources to tap into when caring for a child in a fragile health state. The development of human capital in the presence of self-productivity and dynamic complementarities suggests that investments made at certain points in time, like these investments in vulnerable infants, could be particularly costeffective (Cunha and Heckman, 2007). Our results provide evidence that targeted public programs such as SSI may be one way to narrow the growing divide between children of highand low-educated parents.

\section{Background and Institutional Context}

\section{A. Income Transfers and Child Outcomes}

Income transfers can improve child outcomes through two key channels (Mayer, 1997; Yeung, Linver, and Brooks-Gunn, 2002; Milligan and Stabile, 2011). First, income transfers alleviate credit constraints and enable families to invest more optimally - the "resource" channel. Second, income transfers can reduce stress, which can in turn improve outcomes - the "family process" channel. 
In prior work, authors have shown that income transfers can effectively improve outcomes through these channels. For example, Aizer et al. (2016) examine the Mother's Pension Program and find that a pension award reduces the likelihood of being underweight, increases life expectancy, and increases education and adult earnings. Hoynes, Miller, and Simon (2015) show that the Earned Income Tax Credit improves infant health at birth. Others have shown that the distribution of casino revenues to tribal members improves education and decreases crime (Akee et al., 2010) and improves children's emotional and behavioral health and body mass index (Akee et al., 2013; Akee et al., 2018). The Canadian Child Benefit has been shown to improve educational attainment as well as children's mental and physical health, and the additional income works through both the resource and family process channels (Milligan and Stabile, 2011; Jones, Milligan, and Stabile, 2015). Across these studies, the evidence suggests income transfers are effective, particularly for credit-constrained families. Our work builds upon and expands the findings of this literature by looking at an important public program, and, to our knowledge, we are the first to estimate the causal effects of SSI (an income transfer) during infancy on early childhood outcomes.

\section{B. Supplemental Security Income for Children}

The Supplemental Security Income program was enacted in 1972 to provide means-tested income support to individuals with disabilities and the elderly in the United States. Since its inception, SSI has included payments to children with disabilities ages 0-17. In practice, SSI benefits for children include a bundle of supports: an income transfer, Medicaid eligibility in most states, and referral to other services, such as physical or speech therapy. Although relatively few children received benefits in the early years of the program, since 1990 SSI for children has become an increasingly important part of the safety net (Ben-Shalom, Moffitt, and Scholz, 2012; 
Aizer, Gordon, and Kearney, 2013; National Academies, 2015; Duggan, Kearney, and Rennane, 2016). However, only a handful of studies have focused on the program's effects on child and family outcomes and the effects of receipt during infancy are particularly understudied.

Through the resource channel, an SSI award could relax the budget constraint faced by low-income parents of children with disabilities. Duggan and Kearney (2007) show that families with child SSI recipients are significantly less likely to be poor. SSI could enable parents to purchase goods or services for their disabled child otherwise foregone in absence of the transfer (DeCesaro and Hemmeter, 2009), but no causal evidence exists on this mechanism. ${ }^{5}$ Through the family process channel, the additional resources associated with SSI receipt could alleviate stress.

SSI could also affect parental labor supply. The income associated with receipt could allow a parent to reduce time in the labor market in exchange for time spent with the child rather than trying to meet full time work obligations and the needs of a child with disabilities. In addition, parental income counts against a child's SSI payments, which creates parental work disincentives (Deshpande, 2016a and 2016b; Guldi and Schmidt, 2018). Deshpande (2016a) finds that removal of a child under the age of 13 from SSI leads to an increase in parental labor earnings that fully offsets the lost payment. ${ }^{6,7}$ While this work suggests that SSI affects parental

\footnotetext{
${ }^{5}$ SSA's regulations require a parent (as the representative payee) to spend the child SSI payments exclusively on the child (20 CFR 416.640), (https://www.ssa.gov/pubs/EN-0510076.pdf), although parents may reallocate family resources, including time or monetary resources, when the child receives SSI.

${ }^{6}$ However, Deshpande (2016b) finds that removal of a child from SSI at age 18 has no significant effects on parental income. Kubik (1999) also offers evidence of changes in parental labor supply when a child receives SSI, but Duggan and Kearney (2007) find no such effects. ${ }^{7}$ In related work, researchers have shown that receiving SSI as a child influences labor supply outcomes later in adulthood. Deshpande (2016b) finds that removal of a child from SSI at age 18 significantly reduces own future income and increases income volatility, and Levere (2017)
} 
labor market and economic outcomes, it is not yet known whether SSI for low birth weight infants affects child development or other family outcomes during early childhood.

\section{Child SSI Eligibility for Low Birth Weight Infants}

The typical procedure to determine eligibility for child SSI is twofold. First, SSA determines a child's financial eligibility, where some portion of parental income is deemed to the child. Next, State Disability Determination Services (DDS) assess the child's impairment and determines disability according to SSA rules (Wixon and Strand, 2013). In 1991, SSA defined low birth weight to be a condition "functionally equivalent" to meeting a listing, and infants below certain birth weight cutoffs would be classified as disabled. In 1993, low birth weight became a presumptive disability category, allowing SSA staff in local field offices and disability examiners in DDSs to award time-limited benefits for up to six months to an applicant meeting the birth weight cutoffs while they are awaiting an eligibility determination. In 2015, low birth weight became its own medical listing with the same birth weight criteria defined in 1991. For our study, the policy in place beginning in 1993 is most relevant since the three data sets we use cover years contained in the period 2001 to 2013.

The medical community defines low birth weight as weight less than 2500 grams or 5.5 pounds, and very low birth weight as less than 1500 grams or 3.25 pounds (Maternal and Child Health Bureau, 2013). ${ }^{8}$ Infants born below 2500 grams are at greater risk of diminished shortand long-run health (e.g. Hack et al., 1995; IOM, 2006) and worse economic outcomes (e.g.

shows that increased exposure to SSI benefits during childhood reduces the recipient's labor earnings through age 30 .

${ }^{8}$ The medical community defines extremely low birth weight as less than 1000 grams, but we are unaware of other standard birth weight thresholds below 1500 grams in use by the medical community. 
Oreopoulos et al., 2008; Aarnoudse-Moens et al., 2009). Furthermore, the risk increases nonlinearly the lower the birth weight and/or the earlier the gestation (Alexander et al., 2003;

Behrman and Rosenzweig, 2004; Black, Devereaux, and Salvanes, 2007; Durrance and Guldi, 2015). ${ }^{9}$ This finding suggests that interventions targeting the most vulnerable infants at birth may have the largest effects. The fraction of all live births in the United States that are low birth weight or very low birth weight has risen over the past thirty years, suggesting a growing number of individuals may experience worse health at birth and beyond. ${ }^{10}$

SSA evaluates low birth weight from birth to age one using one of two rules defining this condition. ${ }^{11,12}$ The first, $100.04 \mathrm{~A}$, defines low birth weight as weighing less than 1200 grams regardless of gestational age. The second, 100.04B, considers gestational age together with birth weight and infants light for their gestational age qualify as low birth weight. ${ }^{13}$ Due to data limitations, discussed in detail below, our analysis will focus solely on the 1200-gram threshold. SSA low birth weight criteria are more restrictive than the medical community's definitions for low ( $<2500$ grams) and very low ( $<1500$ grams) birth weight. ${ }^{14}$ SSA uses these low birth

${ }^{9}$ The cost of treating low birth weight infants can be large; in 2001, while only $8 \%$ of all hospitalized infants had a preterm or low birth weight diagnosis, these infants accounted for $47 \%$ of the hospitalization costs (Russell et al., 2007).

${ }^{10}$ The rise in multiple births and increases in obstetric interventions (e.g. C-section births) have contributed to the rise in low and very low birth weight babies (Maternal and Child Health Bureau, 2013). Rates of low birth weight births rose until about 2005, and have fallen since then (see Buckles and Guldi, 2017 for a discussion and possible explanations).

${ }^{11}$ In this paper, when discussing SSI birth weight eligibility we will use "low birth weight" to indicate that an infant falls below SSA's low birth weight cutoffs.

${ }^{12}$ SSA's specific medical criteria for benefits are known as the Medical Listings (or just the Listings) and are found in the Blue Book: https://www.ssa.gov/disability/professionals/bluebook.

${ }^{13}$ Appendix Table 1 provides the birth weight for gestational age cutoffs.

${ }^{14}$ Birth weight is the first weight recorded after birth. Gestational age is the infant's age based on the date of conception. Birth weight and gestational age as observed by SSA come from the original or certified copy of a birth certificate (the same information as reported by the ECLS-B 
weight rules to target infants at risk of longer term disability. The preamble to the original low birth weight regulation (SSA, 1991) states, "[o]ur case experience has shown that infants who demonstrate the kinds of functional deficits that will be required to establish disability [as low birth weight]... are likely to continue to demonstrate that they are disabled when they are older." ${ }^{15}$ The fraction of low birth weight child SSI awards has been roughly 10 percent of all child SSI awards in most recent years. Parental income is not deemed to the child while the child is in a medical institution, but is deemed once the child goes home. Additionally, while the child is in the medical institution and Medicaid or health insurance covers at least 50 percent of the cost of care, the child is only eligible for a reduced SSI payment of up to $\$ 30$.

Infants may stop receiving payments for reasons apart from failing the means-test due to deeming. SSA is required to conduct low birth weight child Continuing Disability Reviews (CDRs) within 1 year of birth, or later if the impairment is not expected to improve within 12 months. In FY 2009 SSA ceased eligibility in 47\% of low birth weight child CDR cases (Hemmeter and Bailey, 2015). According to our calculations using SSA administrative data (available upon request), among children awarded SSI for low birth weight in 2001, 65.8\% were in current pay status at their first birthday, and only $22.9 \%$ still received benefits by their fifth

and the BC-L data) or from a medical record signed by a physician (similar to data reported by the HCUP-SID). In either case birth weight can be reported in ounces or grams. The Childhood Disability Interview checklist prompts parents to bring the child's birth certificate with them when applying for SSI.

${ }^{15}$ If an applicant does not meet the LBW listing, SSA continues with the disability determination process and functionally assesses the child's condition to determine if there are other listing-level impairments or if the child condition functionally equals the medical criteria for SSI. If awarded SSI, the child would not be counted as LBW. 
birthday. As a result, despite long spells for many SSI recipients, the SSI cash transfers to the majority of low birth weight infants can be thought of as relatively short-term.

We study a population particularly suited to benefit from income transfers. First, a given health intervention can be expected to have a higher marginal benefit if initial health is worse. The initial infant health among our study population is well below average. The 1200-gram threshold we study falls below the first percentile of the birth weight distribution of live births in 2001 (NCHS, 2001). Second, prior work shows that the positive benefits of income transfers exhibit the largest effects for individuals from low-SES families. ${ }^{16}$ Since SSI payments are means-tested, families with lower income and fewer outside resources are more likely to continue receiving SSI benefits or to receive higher benefits. As such, we expect the largest effects of these transfers to be concentrated among lower-SES families.

Individuals who receive SSI are typically eligible for Medicaid. ${ }^{17}$ Although the Medicaid coverage associated with SSI receipt could directly affect outcomes, the lower-SES families we focus on would likely qualify for Medicaid coverage without SSI receipt. As a result, SSI is unlikely to change primary insurance coverage in our analysis sample of low-SES families. Still, SSI infants with other sources for primary health insurance may become newly eligible to enroll in Medicaid as a secondary payer. SSA referrals of SSI child awardees to the appropriate state

\footnotetext{
${ }^{16}$ Above, we discuss several studies that specifically show this treatment effect heterogeneity for income transfers. In addition, a number of studies examine other programs and show stronger effects for low-SES groups. For example, the WIC program (Hoynes, Page, Stevens, 2011); the Food Stamp program (Hoynes, Schanzenbach, and Almond, 2016); childcare (Herbst, 2017); and early childhood education (Kearney and Levine, 2015) all benefit individuals from low-SES households more than individuals from high-SES households.

${ }^{17}$ While most SSI recipients receive publicly-provided insurance through the Medicaid program, the way in which the two programs are linked varies by state. Additionally, each state determines the generosity of services covered by its program. See Rupp and Riley (2016) for additional details regarding the links between SSI and Medicaid.
} 
agencies for relevant services under Title V of the Social Security Act (such as physical or speech therapy) could also directly affect outcomes.

\section{Data}

In this paper, we use a regression discontinuity approach to compare SSI receipt and outcomes of children just under the 1200-gram eligibility cutoff to those just above the cutoff. SSA's other birth weight eligibility cutoffs for SSI, described in the Background Section and provided in Appendix Table 1, are specific to gestational age. In order to focus on the effects of SSI at the 1200-gram cutoff, we need data sets that include birth weight, gestational age, the outcomes of interest, and that have sufficient mass around the birth weight thresholds. Few data sets meet this bar. In this section, we describe the three data sets used and their relative strengths and weaknesses. Additionally, as discussed in the Background Section, many public investments benefit the lowest SES groups the most. To focus on these families, we restrict our analysis sample to infants born to low SES mothers.

\section{A. Early Childhood Longitudinal Study, Birth Cohort (ECLS-B)}

The Early Childhood Longitudinal Study, Birth Cohort (ECLS-B) is a nationally representative longitudinal data set collected by the National Center for Education Statistics (NCES). The ECLS-B oversamples children with lower birth weights. The ECLS-B sample is drawn from birth certificate data, and as a result includes many of the variables from the original birth certificate, including birth weight. Figure 1 shows the birth weight distribution of infants born to mothers with a high school degree or less, and makes clear the extent to which the ECLS-B oversamples infants at the lower end of the birth weight distribution. The ECLS-B does not include births to mothers less than age 15 , or children who died or were adopted before the 9- 
month assessment. ${ }^{18}$ The ECLS-B follows children from birth through kindergarten with data collection occurring at approximately 9 months of age, 2 years of age (2003), 4 years of age (at pre-school, fall 2005), and at kindergarten entry. ${ }^{19}$ The 9-month data collection also includes variables from infants' birth certificates. A sample of 10,700 children born in 2001 participated in the first wave of the ECLS-B. ${ }^{20}$

We begin by examining SSI receipt. Importantly, our measure of SSI receipt is from the 2-year wave and asks "Since the last interview, has anyone in the household received SSI/SSDI?” This variable proxies for child SSI receipt, but with measurement error, since it includes receipt from family members other than the focal infant, includes Social Security Disability Insurance (SSDI) as well as SSI, and is from an interview a full year after low birth weight SSI recipients must go through a CDR to reestablish eligibility after one year. However imperfect, it is the best measure of child SSI receipt available in survey data that have sufficient mass around the 1200-gram birth weight and also contain measures of gestation.

In our ECLS-B results, we examine several different child and family outcomes from the 9-month wave. First, we examine measures of health insurance coverage (any, private, public Medicaid or the Children's Health Insurance Program (CHIP)), and whether the infant was ever

${ }^{18}$ This leads to selection of healthier infants on average into the ECLS-B. We study infant death using 2001 BC-L data and do not find evidence that infant mortality changes at the 1200-gram SSI eligibility threshold, so it does not appear that this selection into the ECLS-B sample is related to SSI receipt. (We provide a more detailed discussion of these estimates in the Results section).

${ }^{19}$ In the fall of 2006, NCES collected data on all children, $75 \%$ of whom had entered kindergarten or higher grades. In the fall of 2007, NCES collected data on the remaining $25 \%$ of the children who had not started kindergarten by the previous year, as well as any children repeating kindergarten in the 2007-2008 year.

${ }^{20}$ All ECLS-B reported sample sizes have been rounded to the nearest 50 per NCES restrictions regarding disclosure of restricted use data. However, the analyses and statistics presented in the tables and text are generated using all observations in each subsample. 
without insurance at the 9-month wave. We then examine child outcomes using the Bayley Short Form Research edition measures of children's cognitive development as well as the development of their fine and gross motor skills. We include both the Bayley Mental and Motor scale, and use standardized t-scores (with a mean of 50 and a standard deviation of 10) that adjust for prematurity. Next we examine parental inputs using the Nursing Child Assessment Teaching Scale (NCATS) which assesses parent-child interactions. We include both the parent and child scores. The parent score measures the parent's sensitivity to the child's cues, responsiveness to the child's distress, and fostering of cognitive and socio-emotional growth. The child score measures clarity of the child's cues and the child's responsiveness to the parent. We then look at whether the infant received any of the following services: physical therapy, vision services, hearing services, social work services, psychological services, home visits, and parent support or training. Last, we examine parental outcomes including maternal and paternal labor supply (whether the parent works, works part time, works full time, and hours worked per week) and maternal mental health as measured by a modified 12-item Center for Epidemiological Studies Depression Scale (CESD).

Finally, we use later waves of the ECLS-B to determine whether any effects persist over time. The variables for SSI receipt, health insurance, and maternal labor supply are consistent across all ECLS-B waves: Wave 2 (2-year), Wave 3 (preschool), and Waves 4 and 5 (kindergarten 2006 and 2007). The Bayley Short Form is conducted in Waves 1 and 2. The NCATS is only asked in the 9-month wave, so in Wave 2 we examine parenting behaviors with the Two Bags Test, a semi-structured activity completed by the parent and child. The Two Bags Test measures similar behaviors as the NCATS (parent's sensitivity, parent's stimulation of child's cognitive development, etc.) but the two scales are not directly comparable. 
Summary statistics for our ECLS-B sample, Panel A of Appendix Table $2,{ }^{21}$ reveal just how disadvantaged our sample is; $31 \%$ of our sample report receiving disability benefits at some point between the 9-month and 2-year wave interviews. Our sample also has near universal health insurance coverage (98\%), which is achieved primarily via public coverage (77\%). Although the Medicaid that accompanies SSI receipt could be an important benefit of the program, as we discuss above, gaining primary insurance via Medicaid is unlikely to play much of a role in our sample.

\section{B. The Healthcare Cost and Utilization Project State Inpatient Databases (HCUP-SID)}

The HCUP-SID is a data set of inpatient discharge abstracts from participating states sponsored by the Agency for Healthcare Research and Quality. The data are drawn from $97 \%$ of all U.S. hospital discharges and contain one record per hospital admission ending in discharge or death. Each state-year HCUP-SID database contains a slightly different set of variables. We use the HCUP-SID databases from the University of Michigan Institute for Healthcare Policy and Innovation that report birth weight, year of birth, median household income at the zip code level and unique person identifiers. This yields data from Arkansas (2006-2013), Arizona (20062007), North Carolina (2006-2010), New Mexico (2012), and Vermont (2012). ${ }^{22}$

As we previously describe in the Background Section, SSI enrollment may affect an infant's source of health insurance (Duggan, Kearney and Rennane 2016). Although our low

\footnotetext{
${ }^{21}$ In spite of the oversampling of low birth weight infants, our analysis sample contains only 650 observations, and many of our RD estimates will be identified off of 200-250 observations, limiting the power of our analysis.

22 The SID data partners are the Arkansas Department of Public Health, the Arizona Department of Health Services, the New Mexico Department of Public Health, the North Carolina Department of Health and Human Services, and the Vermont Association of Hospitals and Health Systems.
} 
SES sample may be less affected, we use the HCUP-SID databases to investigate this possibility. First we use the HCUP-SID to look at changes in primary and secondary expected payer of the birth hospitalizations distinguishing between Medicaid, private health insurance, self-pay and other federal or local programs.

As discussed above, we expect the effects of the SSI program to be strongest for individuals with the fewest resources. Unfortunately, our HCUP-SID database does not include individual level variables that could proxy for household resources like mother's education in the ECLS-B. At best we can restrict our sample to infants who reside in low-income zip codes. We acknowledge the HCUP-SID sample is not directly comparable to the ECLS-B sample. The HCUP-SID reports quartile classifications of the estimated median household income for patients’ residence zip code. Specifically, we restrict the sample to infants either homeless at birth or who reside at birth in zip codes in the lowest quartile of the national zip code median household income distribution. For example, in 2014 all infants who reside at birth in zip codes with median household incomes below \$39,999 or below approximately 200\% of the 2014 federal poverty guideline for a family of three would be included. ${ }^{23}$ Our final analysis sample includes 3,600 infants. Appendix Table 2, Panel B presents summary statistics for the HCUPSID analysis sample.

\footnotetext{
${ }^{23}$ However, incomes can vary widely even within a zip code. Furthermore, family size and structure are important determinants of SSI eligibility, so families with different structures but the same income may vary dramatically in their eligibility.
} 


\section{Birth Cohort Linked Birth - Infant Death Data Files (BC-L)}

We also use the National Center for Health Statistics (NCHS) Birth Cohort Linked BirthInfant Death Data file (BC-L), containing information from birth certificates and death certificates for infants who died within one year including: birth weight, gestational age, age in days at death, mother's education at birth and other mother and child characteristics. We limit our sample to infants born in 2001, at 32 weeks gestation or less, and to a mother who has a high school degree or less to match the ECLS-B sample. We use the BC-L data set to investigate the effects of SSI on infant mortality and to examine patterns in infants' baseline characteristics for a larger sample than is available in the ECLS-B. Appendix Table 2, Panel C presents summary statistics for 60,319 live births in this sample.

\section{Methods}

We use a regression discontinuity approach to estimate the impact of SSI eligibility for low birth weight infants on disability benefit receipt and outcomes for infants by comparing those born just under the 1200-gram cutoff for SSI eligibility to those born just above the cutoff. The regression discontinuity design helps credibly isolate the effects of SSI eligibility, which changes sharply at the cutoff, from other factors that also differ by birth weight and could affect the outcomes of interest. Additionally, although we can only measure whether anyone in the household has received SSI/SSDI we would not expect any other family members' SSI/SSDI receipt to change discontinuously at the birth weight threshold. Therefore, using a regression discontinuity approach at the birth weight threshold we likely capture the effect of SSI eligibility on the SSI receipt of the infant themselves. 
We do not use the SSA's other birth weight gestational age cutoffs for several reasons.

First, in the ECLS-B we do not have a sufficient number of infants to separately identify effects at each gestational age-specific birth weight threshold. In addition, we choose not to re-center the running variable within gestational age around each birth weight threshold to run pooled regressions since this could potentially produce biased estimates by picking up the effects of the medical intervention aimed at infants just below the medical 1500-gram cutoff rather than effects of SSI (e.g. Almond et al., 2010). Finally, exploring multiple thresholds in a regression discontinuity model sometimes obscures key differences in effects at different thresholds (Cattaneo et al., 2016). Therefore, we restrict our sample to infants born at 32 weeks gestation or less for whom only the 1200-gram birth weight eligibility threshold applies. ${ }^{24}$

Although infants with birth weight below 1200 grams are categorically eligible for SSI, not everyone enrolls in the program. Furthermore, individuals in our analysis sample above the 1200-gram cutoff may be eligible for SSI depending on other qualifying medical conditions. Therefore, conceptually we implement a fuzzy regression discontinuity design, as the probability of SSI enrollment increases at the 1200-gram cutoff, but not necessarily from 0 to 1 . However, as described in our Data Section, our measure of infant SSI enrollment is quite noisy. As a

\footnotetext{
${ }^{24}$ Infants born at 33 weeks or later face higher birth weight eligibility thresholds. For example, an infant born at 40 weeks gestation is SSI eligible if their birth weight is below 2000 grams. So, these infants with birth weight on either side of the 1200-gram threshold will be program eligible. Infants born at 32 weeks are SSI eligible if their birth weight is 1250 grams or less. Therefore, infants born at 32 weeks with birth weight between 1200-1250 grams will be SSI eligible, but those born at less than 32 weeks with the same birth weights will be ineligible. Since we define SSI eligibility as being below 1200 grams in our regressions, we drop infants born at 33 weeks or later and a handful of infants born at 32 weeks with birth weight between 1200 and 1250 grams. In total, this later restriction eliminates very few observations (rounds to zero) from our ECLS-B sample. If we include these observations, our results are similar, likely because they represent a relatively small portion of the mass above the 1200-gram cutoff.
} 
result, we have not scaled up our estimates of the effect of SSI eligibility on infant outcomes by the first stage, so our estimates should be interpreted as intention-to-treat effects (e.g. Ludwig and Miller, 2007).

We present results from both a linear parametric model and a local linear regression model. The linear parametric model uses a bandwidth choice of 200 grams and bootstrapped standard errors. Therefore, these results are estimated using the same sample for each outcome within each data set. We chose a 200-gram bandwidth to avoid any bias caused from having the bandwidth cross the 1500-gram threshold for medical intervention. The local linear regression model is weighted using a triangular kernel, and run within the data-driven optimal bandwidth chosen by the Calonico et al. (2018) procedure (CCFT procedure). Using the CCFT procedure, we present bias-corrected estimates with robust standard errors. Both of these specifications allow the regression slope to differ on either side of the 1200-gram cutoff. In Section G we test the robustness of our results to alternate specifications.

A key assumption of the RD design is that the running variable (in our case birth weight) evolves smoothly across the threshold. By extension, we assume that potential outcomes also change smoothly at the cutoff. We believe the SSA birth weight eligibility rule provides a setting in which the RD design is likely valid. To the extent possible, we test for and fail to find strong empirical evidence of violations of this assumption.

First, we examine birth weight. If medical professionals report birth weight strategically to take advantage of the SSA cutoffs, this would call into question the validity of our design. ${ }^{25}$

${ }^{25}$ Individuals also have the incentive to manipulate gestational age and/or report a later gestational age since the SSA thresholds for infants born at later gestational ages are even higher than 1200 grams. Even so, there should be no programmatic reason for the gestational ages of 
We investigate this possibility visually by examining histograms of birth weights around the 1200-gram threshold. Histograms for the BC-L data are presented in Figure 2. Panel A is the birth weight distribution of infants born to mothers with a high school degree or less. Panel B is the histogram for our analysis sample (births with gestational age less than or equal to 32 weeks and maternal education of high school or less), and zooms in on the smaller range of birth weights from 500 grams to 2000 grams. These histograms show no obvious evidence of manipulation of birth weights just below the threshold. The ECLS-B and HCUP-SID histograms show very similar patterns - no evidence of strategic manipulation of birthweights, and very similar patterns of heaping. We are unable to present the detailed ECLS-B histogram due to NCES confidentiality restrictions. ${ }^{26}$

However, apparent in our histograms is the substantial heaping of births at round numbers of ounces, and, to a lesser degree at 100-gram intervals. Most of the mass in reported birth weights is at ounce heaps (63\% in our ECLS-B analysis sample, and 66\% in the BC-L analysis sample). Our identification strategy might be compromised if those infants at the heaps were systematically different than those not at the heaps (Barreca et al., 2011; Barreca et al., 2016). Barreca et al. (2016) hypothesize that observed non-random heaping of birth weights may be due in part to lack of precision in hospital scales. The digital scale was first patented in 1980. Barreca et al. (2016) show that the fraction of births at heaps declined dramatically from 1983 to 2002, presumably due in part to improved precision of measured birth weight as hospitals increasingly used digital scales to weigh newborns. Since 2001 is the earliest year used

infants to change discontinuously at 1200 grams. Nonetheless we test for indications of gestational age manipulation in Appendix Table 3 and find none.

${ }^{26}$ HCUP-SID histogram available from authors upon request. 
in our analysis, non-random heaping due to inferior scale technology is less concerning for our analysis. To further explore the possibility that our data exhibits non-random heaping, in Figure 3 we present scatter plot graphs showing infant and maternal characteristics at different heaped and non-heaped birth weights for the ECLS-B, and the results suggest that there are no systematic differences. ${ }^{27}$ However, as a robustness check, we run the regressions only on the heaped data, and results are similar to those from our main sample. Taken together, these exercises suggest that while our data certainly exhibit heaping, we do not see evidence indicating that the heaping is non-random.

We use the Cattaneo, Janson and Ma (2018) approach to manipulation testing and test for a discontinuity in the density of birth weights at the 1200-gram threshold. With both the ECLS-B and the BC-L data (p-values of 0.1650 and 0.8312 respectively) we fail to reject the null hypothesis of no manipulation which provides empirical evidence in favor of the validity of the regression discontinuity design.

We also test for discontinuous changes in infants' baseline characteristics around the cutoff to further probe the assumption that birth weight is locally as good as randomly assigned. Table 1 uses the ECLS-B to examine whether predetermined characteristics exhibit a discontinuity at the 1200 -gram cutoff. ${ }^{28}$ Between the data sets explored, we are able to examine race, child's gender, child's plurality, Apgar score, mother's marital status, and mother's pregnancy risk factors. For most variables, we find no evidence of such a discontinuity, suggesting that infants born just below the cutoff serve as a good comparison group for infants

${ }^{27}$ A corresponding scatter plot using the BC-L is shown in Appendix Figure 1.

${ }^{28}$ Appendix Table 4 does the same for the HCUP-SID and the BC-L. 
born just above the cutoff. ${ }^{29,30}$ One concern is that due to the small sample size in the ECLS-B, some characteristics do exhibit differences around the cutoff that are large in magnitude, even though they are not statistically significant. As an additional robustness check (described in detail in the Results Section), we further test whether our results are driven by a discontinuity in these other characteristics at the birth weight threshold rather than the change in SSI eligibility itself by including these variables as controls in the regressions. Our results remain qualitatively the same.

Importantly, the 1200-gram SSA low birth weight cutoff is not the same as the 1500gram very low birth weight cutoff, which can involve significant medical interventions (Almond et al., 2010). All of the infants on either side of our 1200-gram discontinuity within the 150-gram and 200-gram chosen bandwidths are eligible for those medical interventions. As far as we are aware only one other program, Children's Medicaid in New York State, uses the 1200-gram threshold for eligibility. Until April 2012, among Medicaid enrollees infants with birth weight 1200 grams or less were enrolled in fee-for-service plans for the first 6 months of life while infants with higher birth weights were enrolled in a mandatory managed care program (Lee, 2016). For this reason we have excluded the New York database from our HCUP-SID analysis and have checked the robustness of our ECLS-B and BC-L results to the exclusion of New York.

\footnotetext{
${ }^{29}$ As suggested by Lee and Lemieux (2010) we combine the eleven BC-L tests with a Seemingly Unrelated Regression testing the hypothesis that the discontinuity gap across all questions are jointly equal to zero. The chi-squared test statistic is 10.50 (p-value 0.4857) within a 200-gram bandwidth and 17.76 (p-value 0.0873) within a 150-gram bandwidth, indicating that the discontinuity gaps are not jointly statistically significant.

${ }^{30}$ Exceptions include mother's marital status and parity in the ECLS-B (infants just under the cutoff are more likely to have unmarried mothers and to be first births), and child gender, mother's age, and maternal smoking in the BC-L data (infants just under the cutoff are less likely to be male, have younger mothers, and mothers less likely to have smoked during pregnancy). However, family-wise p-values show no significant results.
} 
We report robust standard errors throughout. Additionally, as we are testing multiple hypotheses, conventional p-values may lead us to incorrectly reject a null hypothesis. We account for this in two ways. First, when outcomes in a group are clearly correlated with each other (such as child development and parenting behaviors), we create an index similar to those implemented by Anderson (2008) and Kling, Liebman, and Katz (2007) by constructing a weighted average of the outcomes (by subtracting the sample mean and dividing by the standard deviation). Second, within families of outcomes, we calculate family-wise p-values using the step-down procedure of Westfall and Young (1993) with 10,000 bootstraps. ${ }^{31}$ These family-wise p-values account for correlations across variables in the data as well as the number of hypotheses being tested.

\section{Results}

\section{A. SSI Eligibility and SSI Enrollment, ECLS-B}

We first establish that a discontinuity exists in receipt of disability benefits at the 1200gram cutoff. Figure 4 Panel A illustrates this graphically, and Table 2 presents estimated RD coefficients and robust standard errors. The first row presents results from the linear polynomial with 200-gram bandwidth model and the second row presents estimates from the local linear regression model with optimal bandwidth choice.

Column 1 of Table 2 Panel A shows that infants born just under the 1200-gram cutoff are significantly more likely to be in families that reported SSI or SSDI receipt in the 2-year ECLSB wave. Estimates from the linear polynomial model with a 200-gram bandwidth imply that low

\footnotetext{
${ }^{31}$ We use the -wyoung- Stata command developed by Jones, Molitor, and Reif (2018).
} 
birth weight SSI eligibility increases the likelihood of family disability benefit receipt by 25 percentage points, significant at the 5-percent level, and the corresponding local linear model shows an effect size of 32 percentage points. These effects are large in magnitude, given that the baseline rate of disability receipt in our sample is $31 \% .^{32}$ Furthermore, the first stage is likely to be an underestimate as the CDR and discontinuation of payments are likely to have occurred for most infants before the 2-year wave interview. As we show below, the first stage effects are larger for those we would expect to be most affected by SSI policies: individuals with prior AFDC receipt, and single mothers.

\section{B. Health Insurance Coverage, ECLS-B and HCUP-SID}

Columns 2-5 of Table 2 Panel A present results for any health insurance coverage, private health insurance coverage, public health insurance coverage (Medicaid plus CHIP), and the probability that the child was ever without insurance coverage. We find no effects of SSI eligibility on overall health insurance coverage or coverage by type. The lack of effects on health insurance coverage may be specific to our sample - with $98 \%$ of our sample reporting health insurance coverage, there may be no room for any measurable effect. These results are also consistent with Duggan and Kearney (2007), who find no effects of SSI for children on health insurance coverage.

In Panel B of Table 2 we examine the relationship between the primary and secondary expected payer of the birth around the SSI eligibility threshold using the HCUP-SID data. Although the ECLS-B results show that SSI eligibility has no discernible effect on Medicaid

${ }^{32}$ We also estimated the effect of SSI eligibility on participation in other social safety net programs (TANF, Food Stamps, and WIC) and found no significant cross-program effects. Results are in the Appendix Table 5. 
coverage overall, the tight link between Medicaid eligibility and SSI might lead to an increase in Medicaid as the secondary payer for SSI eligible infants who have another source of primary health insurance. The analysis using the HCUP-SID data is limited for two reasons. First, not all hospitals in the HCUP-SID report secondary payer information. ${ }^{33}$ Second, some hospitals record the expected payer at hospital admission (before birth weight and gestation are known) and others report the payer from the hospital claims, so measurement error may be an issue. Nevertheless, we find suggestive evidence that the SSI program increases the likelihood that Medicaid is the secondary payer of the birth (Column 5). Results from the local linear model suggests an increase in the likelihood of having Medicaid as a secondary payer by 37 percentage points (on a baseline likelihood of 61\%) significant at the 10 percent level. And, as in the ECLSB, we do not find a statistically significant nor large point estimate of SSI for Medicaid as the primary payer (Column 1).

\section{Infant Mortality, VS-L}

We examine the effects of SSI on infant mortality further using the 2001 Birth Cohort Linked Birth-Infant Death Data file for all states and report these estimates in Table 3. These results examine infant mortality (Column 1), post-neonatal infant mortality (Column 2), and neonatal infant mortality (Column 3). The direction of the estimates is mixed and no estimates are statistically significant. ${ }^{34}$ Taken together these estimates offer little evidence of a relationship between SSI and infant mortality.

${ }^{33}$ In Appendix Table 6 we show that there is no evidence of missing expected payer information systematically differing across the threshold.

${ }^{34}$ We have also performed the analysis for a period that overlaps our HCUP-SID analysis, but for which we do not know the state of birth, as well as for the year 2001 on the subset of states 


\section{Early Child Development and Parenting Behaviors, ECLS-B}

Table 4 examines the effects of SSI eligibility on the Bayley Mental and Motor tests, as well as on the NCATS parent and child scores, all at the 9-month wave. We find positive and significant effects of SSI eligibility on T-Scores for the Bayley Motor test. These results suggest an increase of between 4 and 7 points - roughly half of a standard deviation increase. We also find significant positive effect on parent-child relationships as measured by the NCATS parent test, with coefficients across the specifications suggesting an increase of 3 points, or about a standard deviation increase. We also test for effects on cognitive development, measured using the Bayley Mental test, but these results were inconclusive. Since these variables are all likely to be highly correlated, we also create a summary index as in Anderson (2008) to reduce the number of tests conducted. This index also shows a significant discontinuity at the 1200-gram cutoff, as shown in Column 5.

SSI eligibility for low birth weight infants appears to have positive effects on both child motor skill development and parenting behaviors at 9 months. One possible explanation for these findings, (as discussed in the Background Section), is that SSI, by in part replacing parental earned income, affords parents additional time to invest in their children. We examine the intention-to-treat effects of SSI receipt on parental labor supply in Table 5. In Panel A, we examine maternal labor supply. Although we find no significant effects of SSI receipt on the extensive margin of maternal labor supply (Column 1), we do find that mothers of infants just under the 1200-gram cutoff are less likely to work full time (Column 2) and significantly more

also available for our HCUP-SID analysis. These estimates are similarly mixed in sign and none are statistically significant. Results available from authors upon request. 
likely to work part time (Column 3). Results from the linear polynomial model with 200-gram bandwidth suggest a decrease in full time work of 21 percentage points (on a baseline likelihood of 23\%), and an increase in part time work of 19 percentage points (on a baseline probability of 19\%). Last, we examine the number of hours worked (Column 4), and find a significant decrease of between 18 and 20 paid hours per week, depending on the specification. ${ }^{35}$

These results suggest that SSI eligibility could affect family outcomes by freeing up some time for mothers of these particularly vulnerable infants. In 2001, 20 fewer hours worked at the federal minimum wage of $\$ 5.15$ would have translated into approximately \$446 in lost monthly earnings. The average monthly SSI benefit for child beneficiaries in that same year was $\$ 476$ (SSA, 2002). These results accord with Desphande (2016a), who finds that parents increase their earnings to fully offset their child's loss of SSI. We offer symmetric evidence that parents reduce their work time when their child receives SSI. ${ }^{36}$

In Table 5, Panel B, we examine paternal labor supply. Unlike the large changes shown by mothers, we are unable to draw conclusions regarding fathers' labor supply. That we find strong effects for women and not men is not surprising since both single mothers and partnered women, who are more likely to be secondary earners, typically have higher labor supply elasticities than men (Guldi and Schmidt, 2018).

${ }^{35}$ Actual hours worked are reported by respondents, and the variables for part-time and full-time work are created by NCES from the numerical hours variable.

${ }^{36}$ In results available from the authors, we examine a modified 12-item CESD as a measure of maternal mental health. We find no significant effects of SSI eligibility on the CESD, and the point estimates are small relative to the average CESD score in our sample of 5. We also examine if SSI eligibility affects whether the child received any services for their special needs. The coefficients of interest are imprecisely estimated, but suggestive of a 10-15 percentage point increase in the likelihood of receiving any services among infants with special needs. 


\section{E. Heterogeneity of Effects}

We next examine whether our results are heterogeneous by prior exposure to the welfare system. The ECLS-B asks whether the parent of the focal child was themselves a child in a family that received Aid to Families with Dependent Children (AFDC). In Table 6, we break results out by this indicator. In the interest of space, we show results only for the 200-gram bandwidth linear specification. For most of our variables of interest (SSI receipt, child development and parenting behaviors, and maternal labor supply), the point estimates are much larger for children of mothers who received AFDC as a child. One way to interpret these results is that mothers with previous exposure to the welfare system might benefit more from or have more knowledge about SSI, or feel less stigma about benefit receipt. Another possibility is that this measure picks up otherwise unobservable differences in disadvantage that cause the effects to be larger.

\section{F. Do Effects Persist over Time?}

As noted above, most low birth weight SSI recipients receive cash transfers for a relatively short period of time. As such, we might not expect the effects seen at 9-months in the ECLS-B to persist. We use later waves of the ECLS-B where possible to test this hypothesis and report the estimates in figures. All figures show results from the 200-gram bandwidth linear regressions. Panel B of Figure 4 shows the effect on family disability benefit receipt over time. Our first stage effect is largest in Wave 2 (2-years), which is the first time we can measure SSI receipt with our data.

Figure 5 shows the Bayley Mental (Panel A) and Motor (Panel B) tests as measures of child development, which NCES collected at the 9-month and 2-year waves. These graphs and the corresponding regressions show no discernable effects on either test in the second wave. As 
described in the Data section, the ECLS-B measures parenting behaviors differently in Wave 2, so instead of the NCATS, we look at the Two Bags Test measures of parental supportiveness. We find no significant effects of SSI eligibility on parenting behaviors at 2-years.

Figure 6 examines effects on maternal labor supply over time. We see no significant effects of whether the mother works in any wave of the sample (Panel A). The decrease in full time work is largely limited to the 9-month wave, with closer to a zero point estimate in subsequent waves (Panel B). However, our results suggest an increase in part-time work at 2years and preschool relative to mothers of infants with weight just above the cutoff. These later effects are approximately half the magnitude of the original 9-month effects (Panel C). The effects on hours worked echo this pattern (Panel D). Overall, these results suggest that SSI transfers received by low birth weight infants, many who receive benefits for less than one year, result only in short-term effects for this population.

\section{G. Robustness Checks}

We conduct a wide range of specification checks. Table 7 contains estimates for alternative specifications using the ECLS-B: a linear polynomial model with 150-gram bandwidth, and for a quadratic polynomial model for both a 150-gram and a 200-gram bandwidth. Our results are also largely robust to including a wide range of control variables, including the child's gender and race, mother's marital status, pregnancy risk factors, whether the infant is a twin or a higher order multiple. Additionally, in the ECLS-B we control for whether a smoker lives in the home, whether a drug user lives in the home, and whether English is the primary language spoken at home. In general, our key results are largely robust to these tests, although the magnitude and significance of the coefficient on the Bayley motor skills test 
both fall when covariates are included, which could suggest that these results are partially driven by other factors.

Next, in Table 8 we check the robustness of our baseline results (column 1) to alternative samples and show that they are also robust to limiting the sample to infants with birth weight at ounce heaps (column 2), as well as to omitting New York (column 3). ${ }^{37}$ Table 8 also shows falsification tests at placebo thresholds and for higher-SES samples. We find no effects for most outcomes at placebo cutoffs (1100 grams or 1300 grams, columns 4 and 5) and no evidence of effects for more educated mothers (column 6). ${ }^{38}$

\section{Discussion and Conclusion}

Low birth weight infants born to mothers with low educational attainment have a double hurdle to overcome in the production of human capital. In this paper we examine whether public transfers in the form of SSI income payments and its related benefits can help improve child health and development, and in doing so perhaps help to close the gap between high- and lowSES children's outcomes due to differences in initial health and environmental disadvantage. Using a regression discontinuity approach, we find that SSI eligibility for low birth weight infants increases receipt of family disability benefits, but has no effect on overall health insurance coverage (perhaps unsurprising given the near universal coverage in our sample). We provide suggestive evidence that SSI eligibility increases the use of Medicaid as a secondary

\footnotetext{
${ }^{37}$ Appendix Tables 7 and 8 contain the corresponding robustness checks for the HCUP-SID and BC-L. The HCUP-SID results show that we find no evidence of effects for infants who live in wealthier zip codes.

${ }^{38}$ One exception is that mother's full-time work appears to be significantly higher for those infants just under 1100 grams.
} 
payer, but do not find evidence that it reduces infant mortality. In addition, SSI eligibility significantly improves infant development of early motor skills and parenting behaviors, and reduces maternal labor supply on the intensive margin.

Many of our key results are found using the ECLS-B. As such, the usual caveats of studies on a single cohort, in this case individuals born in 2001, apply. We also caution that while these results are credible for the target group, very low birth weight infants in families with few resources, we would not necessarily expect to find similar effects for individuals of higher birth weight and our robustness checks show generally no evidence of an effect for individuals born into families with greater resources. Even so, our findings are policy relevant since extremely low birth weight infants are over-represented in terms of treatment costs.

Our results are important for several reasons. First, we provide credible estimates of a positive effect of SSI on child health outcomes as measured by the Bayley Motor test. Causal estimates are an important contribution since the government spends a large number of public dollars on SSI each year (over $\$ 54$ billion overall, and over $\$ 9$ billion on children (SSA 2017)), yet the impacts of this expenditure are not well understood. Second, we provide further evidence that post-birth investment made early in childhood can have meaningful effects on child health, and that the effects appear to be concentrated among the segment of the population with the fewest resources. Last, our results indicate that low birth weight SSI does not appear to lead to permanent reduction in maternal labor force participation. Rather, the SSI payments (relatively short-term for many of the infants) support children (and consequently their families) during early childhood, with no persistent labor supply effects in later waves.

The effects we estimate are contemporaneous with benefit receipt and do not persist, at least over the time window as measured by the ECLS-B. This fade out is not completely 
surprising given the size and the duration of the benefits. A family with a recipient that received the average monthly SSI child benefit of \$476 in 2001 for one year would have received approximately $\$ 5700$ in additional income (plus Medicaid). ${ }^{39}$ This is a relatively small public investment over a short period. Any long run effects are likely to be difficult to measure. However, from a social welfare perspective, there may be value in increasing the choice set of parents, who may reduce labor supply to care for or spend time with a vulnerable infant, even if the long-term effects of these choices are not yet known, or in alleviating some of the stress the family experiences when caring for the child, which could also influence long-run outcomes (Akee et al., 2018; Currie and Rossin-Slater, 2015; Jones, Milligan, and Stabile, 2015; Almond, Currie and Duque, 2017). Given that the ECLS-B does not permit us to look beyond a certain window, future work could use administrative data to examine longer-term academic and employment effects of low birth weight SSI receipt.

${ }^{39}$ Actual benefits for an infant eligible due to birth weight are likely to be lower, as many of these infants will spend one or two months in the hospital and receive only $\$ 30$ per month. An infant in the hospital for two months who then received the average benefit for the remaining 10 months would receive an annual income of $\$ 4820$. 


\section{References}

Aarnoudse-Moens, Cornelieke Sandrine Hanan, Nynke Weisglas-Kuperus, Johannes Bernard van Goudoever, and Jaap Oosterlaan. 2009. "Meta-Analysis of Neurobehavioral Outcomes in Very Preterm and/or Very Low Birth Weight Children.” Pediatrics 124(2): 717-728.

Aizer, Anna. 2014. "Rising Inequality and Intergenerational Mobility: The Role of Public Investments in Human Capital.” CESifo Economic Studies, 60(2): 280-311.

Aizer, Anna and Janet Currie. 2014. "The Intergenerational Transmission of Inequality: Maternal Disadvantage and Health at Birth." Science 344(6186): 856-861.

Aizer, Anna, Shari Eli, Joseph Ferrie, Adriana Lleras-Muney. 2016. "The Long Term Impact of Cash Transfers to Poor Families.” American Economic Review 106(4): 935-71.

Aizer, Anna, Nora Gordon, and Melissa Kearney. 2013. "Exploring the Growth of the Child SSI Caseload in the Context of the Broader Policy and Demographic Landscape,” NBER Disability Research Consortium Working Paper NB13-02.

Akee, Randall, William Copeland, Gordon Keeler, Adrian Angold, and E. Jane Costello. 2010. "Parents’ Incomes and Children's Outcomes: A Quasi-Experiment Using Transfer Payments from Casino Profits.” American Economic Journal: Applied Economics, 2(1): 86-115.

Akee, Randall, Emilia Simeonova, William Copeland, Adrian Angold, and E. Jane Costello. 2013. "Young Adult Obesity and Household Income: Effects of Unconditional Cash Transfers.” American Economic Journal: Applied Economics, 5(2): 1-28

Akee, Randall, Emilia Simeonova, E. Jane Costello, and William Copeland. 2018. "How Does Household Income Affect Child Personality Traits and Behaviors?” American Economic Review 108(3): 775-827.

Alexander, Greg R., Michael Kogan, Deren Bader, Wally Carlo, Marilee Allen, and Joanne Mor. 2003. "U.S. Birth Weight/Gestational Age-Specific Neonatal Mortality: 1995-1997 Rates for Whites, Hispanics and Blacks.” Pediatrics 111 (1): e61-e66.

Almond, Douglas and Janet Currie 2011. "Human Capital Development Before Age Five,” in Handbook of Labor Economics, Edited by David Card and Orley Ashenfelter, Volume 4, Part B, Chapter 15, Pages 1315-1486.

Almond, Douglas, Janet Currie and Valentina Duque. 2017. "Childhood Circumstances and Adult Outcomes: Act II,” National Bureau of Economic Research Working Paper No. 23017.

Almond, Douglas, Joseph J. Doyle Jr., Amanda E. Kowalski and Heidi Williams. 2010. Estimating Marginal Returns to Medical Care: Evidence from At-risk Newborns. Quarterly Journal of Economics 125(2): 591-634.

Autor, David, David Figlio, Krzysztof Karbownik, Jeffrey Roth, and Melanie Wasserman. 2016. "Family Disadvantage and the Gender Gap in Behavioral and Educational Outcomes". National Bureau of Economic Research Working Paper No. 22267.

Bailey, Michelle Stegman and Jeffrey Hemmeter. 2015. "Characteristics of Noninstitutionalized DI and SSI Program Participants, 2013 Update.” Social Security Office of Retirement and Disability Policy Research Note 2015-02.

Barreca, Alan I., Melanie Guldi, Jason M. Lindo and Glen R. Waddell. 2011. "Saving Babies? Revisiting the Effect of Very Low Birth Weight Classification.” Quarterly Journal of Economics 126 (4), 2117-2123.

Barreca, Alan I., Jason M. Lindo, and Glen R. Waddell. 2016. “Heaping-Induced Bias in Regression-Discontinuity Designs.” Economic Inquiry 54(1): 268-293. 
Behrman, Jere R. and Mark R. Rosenzweig, 2004. "Returns to Birthweight." The Review of Economics and Statistics, 86(2): 586-601, 06.

Ben-Shalom, Yonatan, Robert A. Moffitt, John Karl Scholz, 2012. "An Assessment of the Effectiveness of Anti-Poverty Programs in the United States.” In The Oxford Handbook on the Economics of Poverty, Philip N. Jefferson, editor. Oxford: Oxford University Press.

Black, Sandra, Paul Devereaux, Kjell Salvanes. 2007. "From the Cradle to the Labor Market? The Effect of Birth Weight on Adult Outcomes", Quarterly Journal of Economics, 122(1): 409-439.

Buckles, Kasey and Melanie Guldi. 2017. "Worth the Wait? The Effect of Early-term Birth on Maternal and Infant Health.” Journal of Policy Analysis and Management 36(4): 748-72.

Cattaneo, Matias D., Luke Keele, Rocio Titunik, Gonzalo Vazquez-Bare. 2016. "Interpreting Regression Discontinuity Designs with Multiple Cutoffs.” Journal of Politics 8(4): 12291248.

Cattaneo, Matias. D., Michael Jansson, and Xinwei Ma. 2018. "Manipulation Testing based on Density Discontinuity.” The Stata Journal 18(1): 234-261.

Calonico, Sebastian, Matias D. Cattaneo, Max Farrell and Rocio Titiunik. Forthcoming 2018. "Regression Discontinuity Designs Using Covariates.” Review of Economics and Statistics 100(3).

Cunha, Flavio and James Heckman, 2007. "The Technology of Skill Formation." American Economic Review 97(2): 31-47.

Currie, Janet. 2011. "Inequality at Birth: Some Causes and Consequences.” National Bureau of Economic Research Working Paper No. 16798.

Currie, Janet and Maya Rossin-Slater. 2015. "Early-Life Origins of Life-Cycle Well-Being: Research and Policy Implications.” Journal of Policy Analysis and Management 34(1): 208-242.

DeCesaro, Anne and Hemmeter, Jeffrey. 2009. "Unmet health care needs and medical out-ofpocket expenses of SSI children.” Journal of Vocational Rehabilitation 30(3): 177-199.

Deshpande, Manasi. 2016a. "The Effect of Disability Payments on Household Earnings and Income: Evidence from the SSI Children's Program." Review of Economics and Statistics 98 (4):638-654.

Deshpande, Manasi. 2016b. "Does Welfare Inhibit Success? The Long-Term Effects of Removing Low-Income Youth from Disability Insurance.” American Economic Review 106(11): 3300-3330.

Duggan, Mark G. and Melissa Schettini Kearney. 2007. "The Impact of Child SSI Enrollment on Household Outcomes.” Journal of Policy Analysis and Management 26: 861-885.

Duggan, Mark, Melissa S. Kearney, and Stephanie Rennane. 2016. “The Supplemental Security Income Program.” In Economics of Means-Tested Transfer Programs in the United States, volume 2, Robert A. Moffitt, editor. Chicago: University of Chicago Press.

Durrance, Christine and Melanie Guldi, 2015. "Maternal Bedrest and Infant Health", American Journal of Health Economics 1(3): 345-373.

Economic Report of the President. 2016 "Inequality in Early Childhood and Effective Public Policy Interventions.” Chapter 4. https://www.whitehouse.gov/administration/eop/cea/economic-report-of-thePresident/2016. 
Guldi, Melanie, and Lucie Schmidt, 2018. “Taxes, Transfers, and Women’s Labor Supply.” in Oxford Handbook on the Economics of Women, ed. Susan L. Averett, Laura M. Argys and Saul D. Hoffman. New York: Oxford University Press.

Hack, Maureen, Nancy K. Klein, and H. Gerry Taylor. 1995. "Long-term Developmental Outcomes of Low Birth Weight Infants.” Future Child 5(1):176-96.

Hemmeter, Jeffrey and Michelle Stegman Bailey. 2015. "Childhood Continuing Disability Reviews and Age-18 Redeterminations for Supplemental Security Income Recipients: Outcomes and Subsequent Program Participation” Research and Statistics Note No. 2015-03

Herbst, Chris M. 2017. “Universal Child Care, Maternal Employment, and Children’s Long-Run Outcomes: Evidence from the U.S. Lanham Act of 1940.” Journal of Labor Economics 35(2): 519-564.

Hoynes, Hilary, Diane Whitmore Schanzenbach, and Douglas Almond. 2016. "Long Run Impacts of Childhood Access to the Safety Net.” American Economic Review 106(4): 903-934.

Hoynes, Hilary, Doug Miller, and David Simon. 2015. "Income, the Earned Income Tax Credit, and Infant Health.” American Economic Journal: Economic Policy 7(1): 172-211.

Hoynes, Hilary, Marianne Page, and Ann Huff Stevens. 2011. "Can Targeted Transfers Improve Birth Outcomes? Evidence from the Introduction of the WIC Program.” Journal of Public Economics 95(7-8): 813-827.

Institute of Medicine (IOM). 2006. "Preterm Birth: Causes, Consequences, and Prevention.” Report Brief, July.

Jones, Damon, David Molitor, and Julian Reif. 2018. "What Do Workplace Wellness Programs Do? Evidence from the Illinois Workplace Wellness Study.” National Bureau of Economic Research Working Paper 24229.

Jones, Lauren E., Kevin S. Milligan, and Mark Stabile. 2015. "Child Cash Benefits and Family Expenditures: Evidence from the National Child Benefit.” National Bureau of Economic Research Working Paper No. 21101.

Kalil, Ariel, Rebecca Ryan and Michael Corey. 2012. “Diverging Destinies: Maternal Education and the Developmental Gradient in Time with Children” Demography 49(4): 1361-1383.

Kearney, Melissa and Philip Levine. 2015. "Early Childhood Education by MOOC: Lessons from Sesame Street.” National Bureau of Economic Research Working Paper No. 21229.

Kubik, Jeffrey D. 1999. "Incentives for the Identification and Treatment of Children with Disabilities: The Supplemental Security Income Program.” Journal of Public Economics 73: 187-215.

Lee, David S. and Thomas Lemieux. 2010. “Regression Discontinuity Designs in Economics,” Journal of Economic Literature 48: 281-355

Lee, Ajin. 2016. "How Do Hospitals Respond to Managed Care? Evidence from At-Risk Newborns” Working Paper, Columbia University.

Levere, Michael. 2017. “The Labor Market Consequences of Receiving Disability Benefits During Childhood.” Working Paper, Mathematica Policy Research Inc.

Ludwig, Jens and Douglas L. Miller. 2007. “Does Head Start Improve Children’s Life Chances? Evidence from a Regression Discontinuity Design.” Quarterly Journal of Economics 122 (1): 159-208. 
Maternal and Child Health Bureau. 2013. Child Health USA 2013. Technical report, Rockville, Maryland.

Mayer, Susan E. 1997. What Money Can't Buy: Family Income and Children's Life Chances. Harvard University Press.

Milligan, Kevin and Mark Stabile. 2011. "Do Child Tax Benefits Affect the Well-being of Children? Evidence from Canadian Child Benefit Expansions.” American Economic Journal: Economic Policy 3:175-205.

National Academies of Sciences, Engineering, and Medicine. 2015. Mental disorders and disabilities among low-income children. Washington, DC: The National Academies Press.

National Center for Health Statistics. Birth Cohort Linked Birth - Infant Death Data Files, 2001. Public-use data file and documentation. https://www.cdc.gov/nchs/data_access/vitalstatsonline.htm

Oreopoulos, Philip, Mark Stabile, Randy Wald, and Leslie L. Roos. 2008. "Short-, Medium-, and Long-Term Consequences of Poor Infant Health: An Analysis Using Siblings and Twins.” Journal of Human Resources 43(1): 88-138.

Rupp, Kalman and Gerald F. Riley. 2016. "State Medicaid Eligibility and Enrollment Policies and Rates of Medicaid Participation among Disabled Supplemental Security Income Recipients.” Social Security Bulletin, 76(3):17-40.

Russell, Rebecca, Nancy Green, Claudia Steiner, Susan Meikle, Jennifer Howse, Karalee Poschman, Todd Dias, Lisa Potetz, Michael Davidoff, Karla Damus, and Joann Petrini. 2007. "Cost of Hospitalization for Preterm and Low Birth Weight Infants in the United States.” Pediatrics 120(1), e1-e9.

Social Security Administration. 2017. Annual Report of the Social Security System https://www.ssa.gov/oact/ssir/SSI17/ssi2017.pdf

Social Security Administration. 2015. “Program Operations Manual System (POMS) Section DI 25235.006. Medical Diary Criteria for Low Birth Weight (LBW) Infants under Title XVI.” https://secure.ssa.gov/poms.nsf/lnx/0425235006

Social Security Administration. 2002. "Fast Facts and Figures about Social Security." (https://www.ssa.gov/policy/docs/chartbooks/fast_facts/2002/fast_facts02_text.html\#char t34)

Social Security Administration. 1991. "Supplemental Security Income; Determining Disability for a Child Under Age 18 (Final Rules with Request for Comments; 56 FR 5534 February 11, 1991)” Hallex II-4-1-1.

Tambornino, John, Gilbert Crouse, and Pamela Winston. 2015. "National Trends in the Child SSI Program” Washington DC: Office of the Assistant Secretary for Planning and Evaluation, U.S. Department of Health and Human Services.

Wittenburg, David, John Tambornino, Elizabeth Brown, Gretchen Rowe, Mason DeCamillis, and Gilbert Crouse. 2015. "The Child SSI Program and the Changing Safety Net." Washington DC: Office of the Assistant Secretary for Planning and Evaluation, U.S. Department of Health and Human Services.

Wixon, Bernard and Alexander Strand. 2013. "Identifying SSA's Sequential Disability Determination Steps Using Administrative Data.” Social Security Administration Note No. 2013-01. 
Yeung, W. Jean, Miriam R. Linver, and Jeanne Brooks-Gunn. 2002. "How Money Matters for Young Children’s Development: Parental Investment and Family Processes. Child Development 73(6): 1861-79. 
Figure 1: Histogram of Birth Weight, ECLS-B

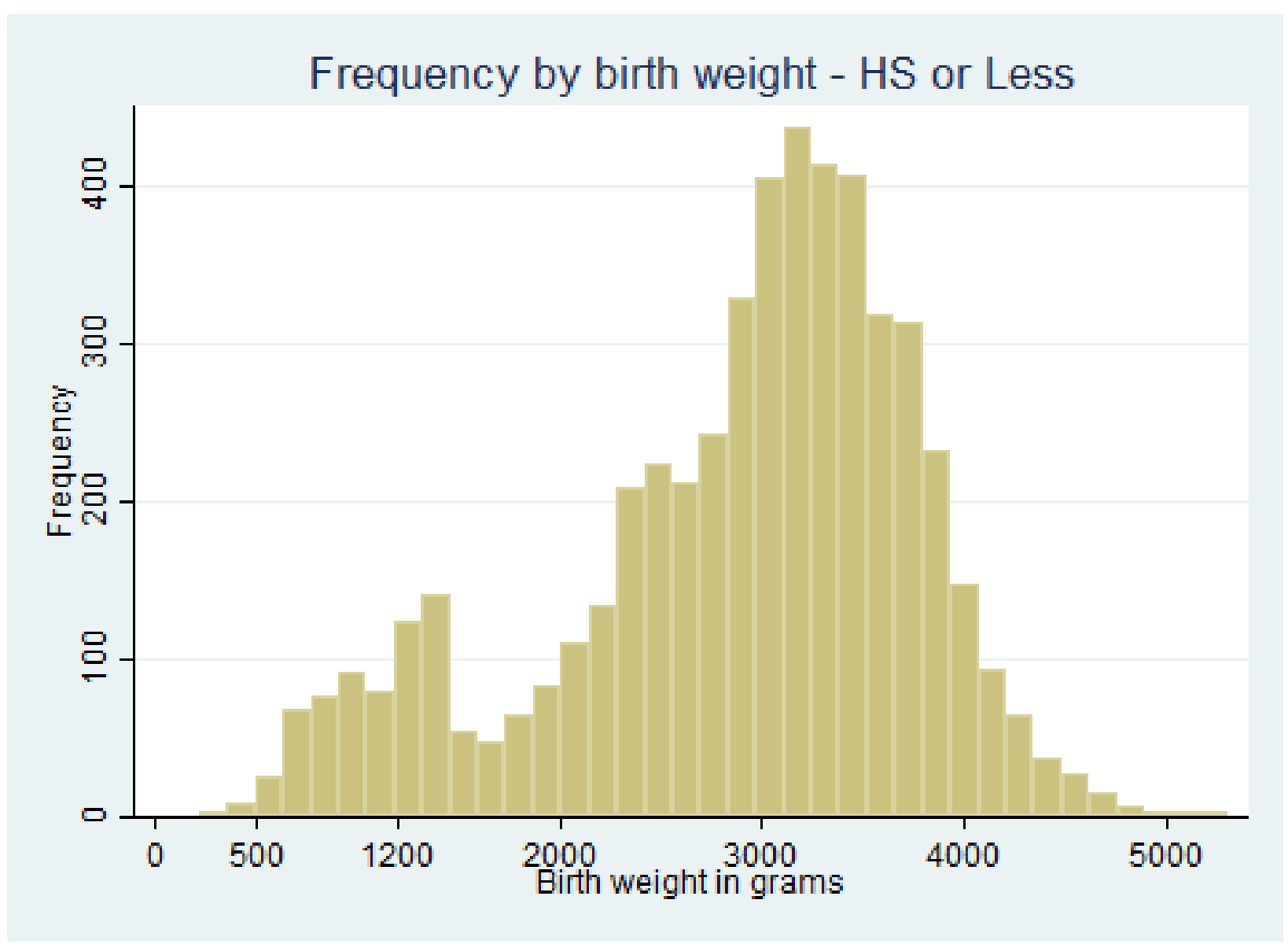

Notes: Data source is ECLS-B. 
Figure 2: Histogram of Birth Weight, BC-L

\section{Panel A:}

Full Sample with high school or less

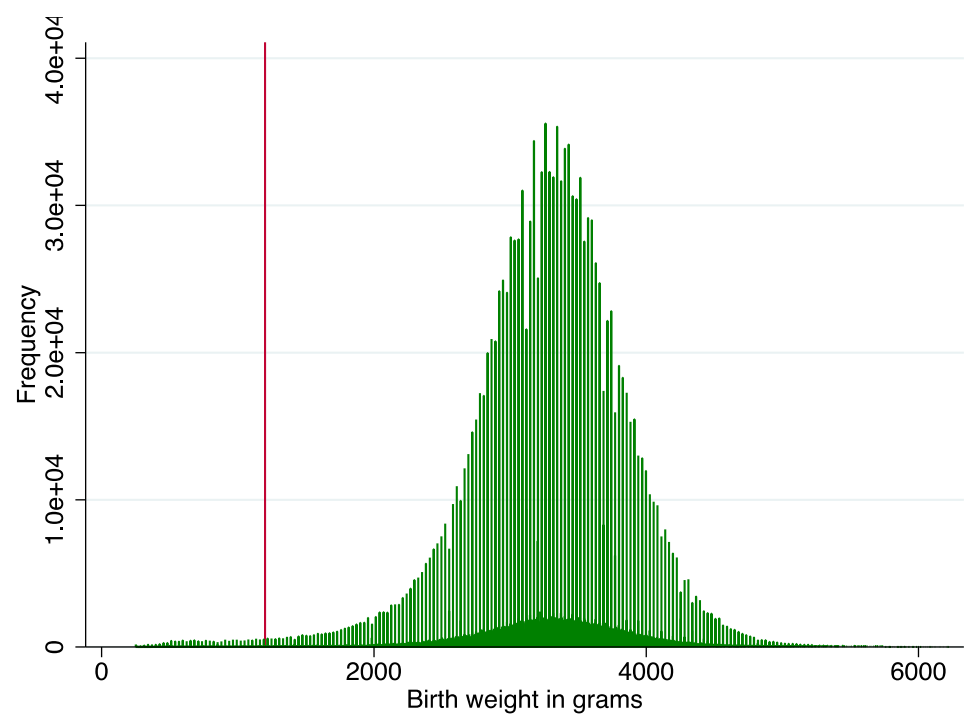

\section{Panel B:}

Sample with high school or less, between 500 \& 2000 grams

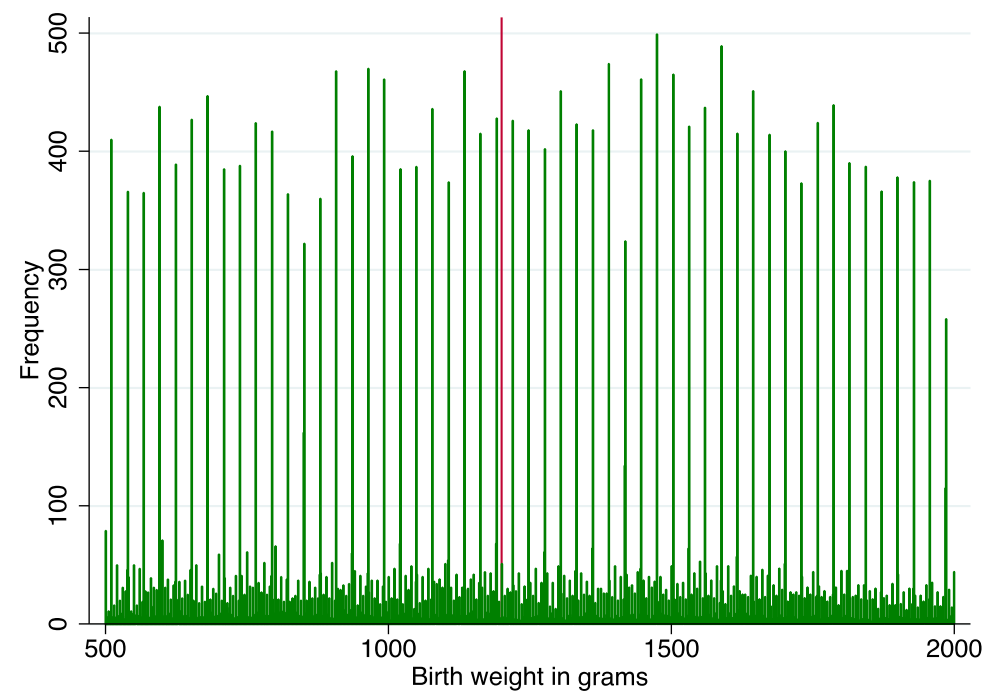

Notes: Frequency of observations by birth weight, Birth Cohort Linked Birth-Infant Death Data file (BC-L)Panel A includes all births to mothers with a high school degree or less, while Panel B includes births to mothers with a high school degree or less and gestation less than or equal to 32 weeks, where birth weight is between 500 and 2000 grams. 
Figure 3: Selected Characteristics at Ounce and 100-gram Multiples, Analysis sample with high school or less, <= 32 weeks gestation (ECLS-B)
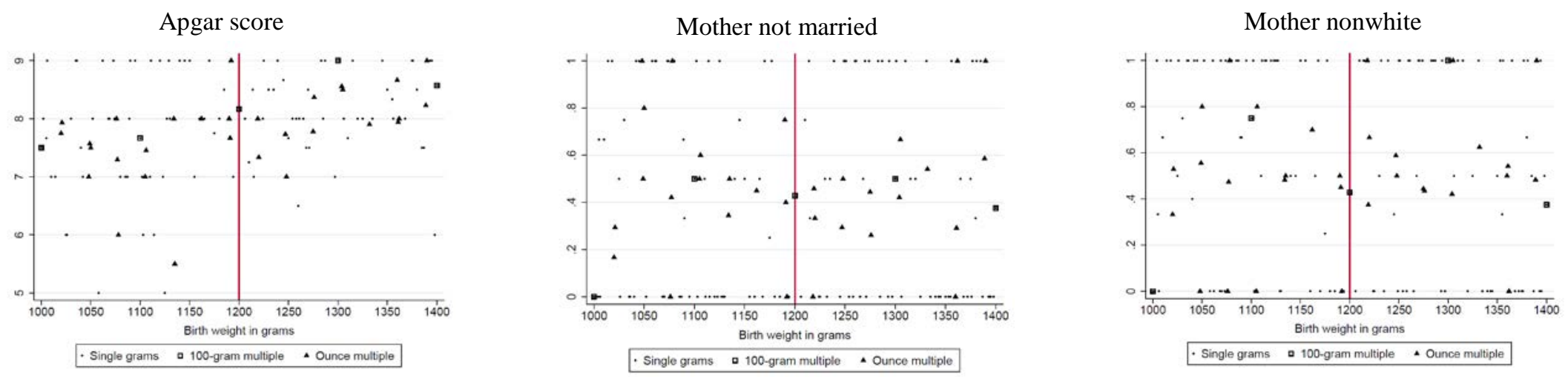

Notes: Data source is ECLS-B. Sample is limited to infants with mother with a high school degree or less and gestational age $<=32$ weeks. Infants born at 32 weeks between 1200 and 1250 grams were dropped from the sample. 


\section{Figure 4: Effects of SSI Eligibility on SSI/SSDI receipt}

\section{Panel A: 2-year Wave}

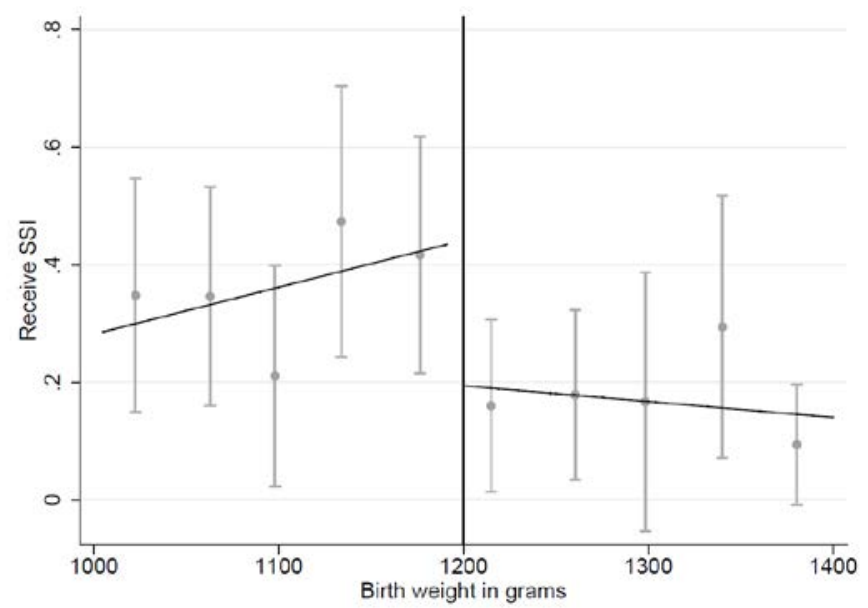

\section{Panel B: Over Time}

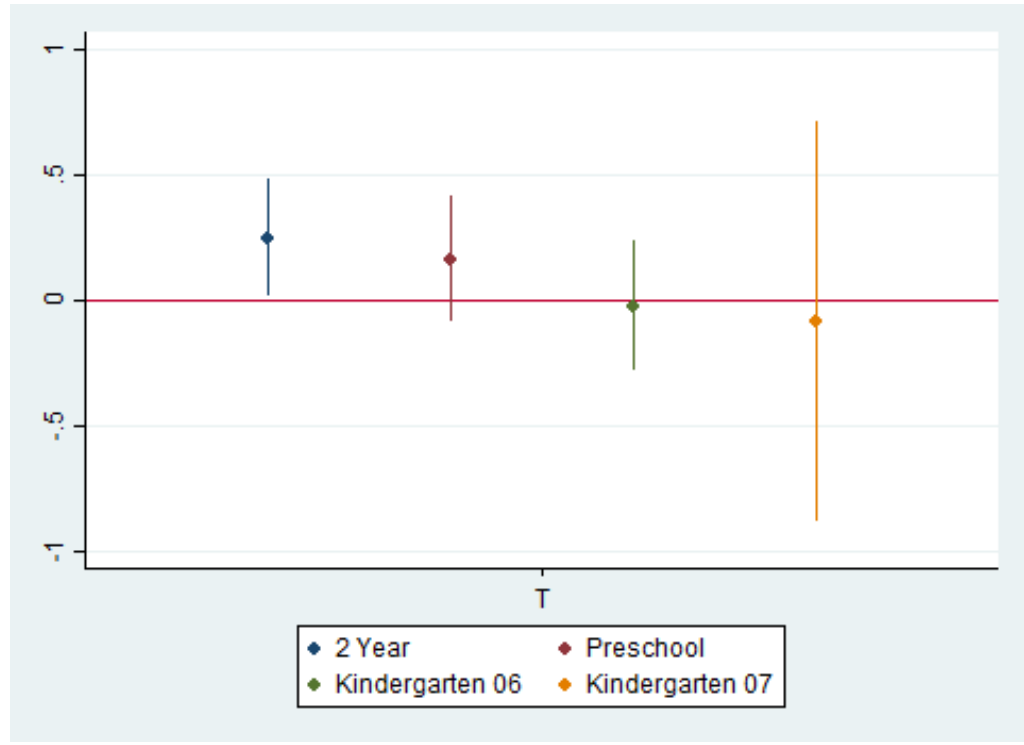

Notes: Data source is ECLS-B. Sample is limited to infants with mother with a high school degree or less and gestational age <=32 weeks. Infants born at 32 weeks between 1200 and 1250 grams were dropped from the sample. Panel A presents the probability of SSI/SSDI receipt (by a family member at the 2-year wave) by birthweight with evenly spaced bins, fit to a first order polynomial on either side of the threshold. In Panel B, each point represents a regression coefficient from a linear parametric specification with a $200 \mathrm{~g}$ bandwidth where the outcome is SSI/SSDI receipt from a different wave. SSI/SSDI receipt is not asked in the 9-month wave. 


\section{Figure 5: Effects of SSI Eligibility on Child Development over time, ECLS-B}

\section{Panel A: Bayley Mental}

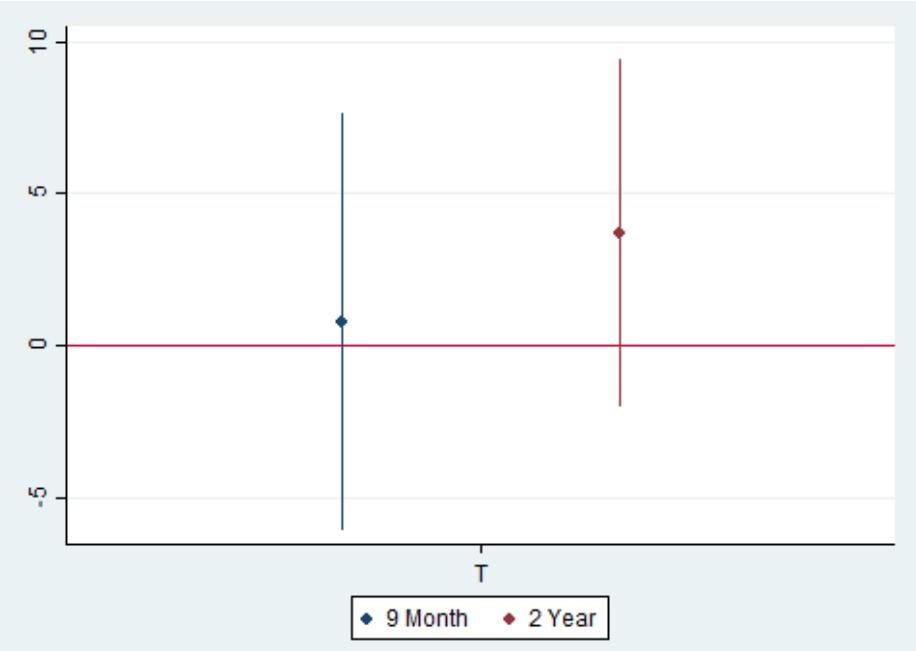

\section{Panel B: Bayley Motor}

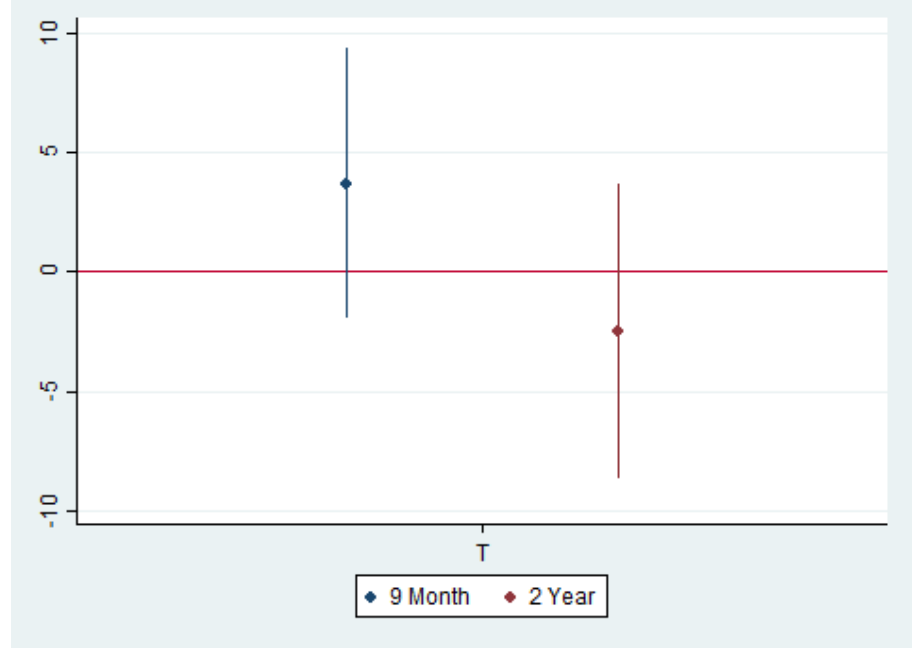

Notes: See notes to Figure 3. In Panel A, each point represents a regression coefficient from a linear parametric specification with a $200 \mathrm{~g}$ bandwidth where the outcome is the Bayley mental score from a different wave. In Panel $\mathrm{B}$, each point represents a regression coefficient from a linear parametric specification with a $200 \mathrm{~g}$ bandwidth where the outcome is the Bayley motor score from a different wave. The Bayley measures are not available past the 2-year wave. 
Figure 6: Effects of SSI Eligibility on maternal labor supply over time, ECLS-B

\section{Panel A: Mother works}

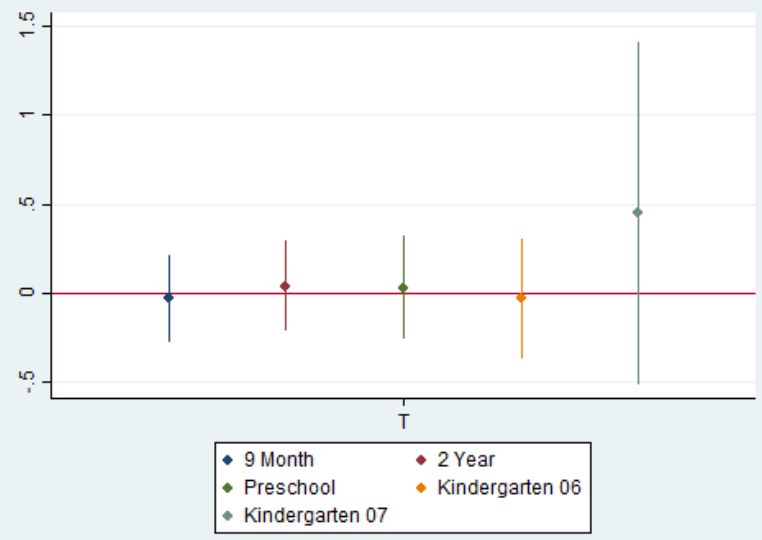

\section{Panel C: Mother works part time}

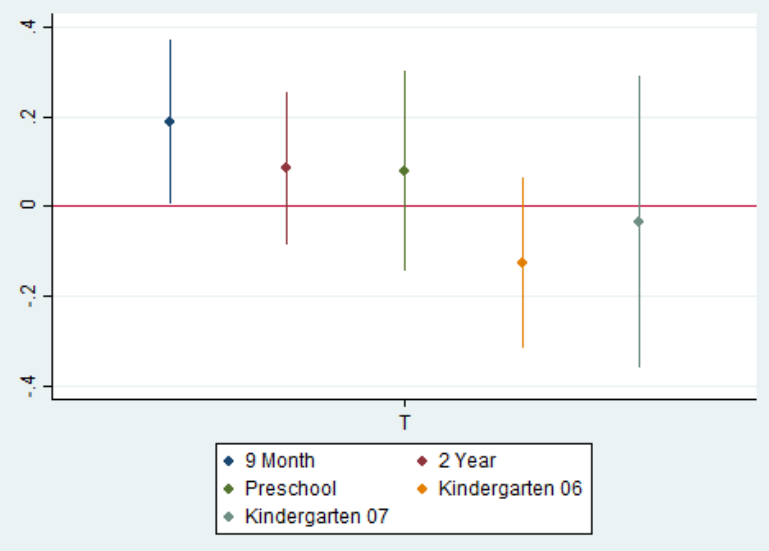

Panel B: Mother works full time

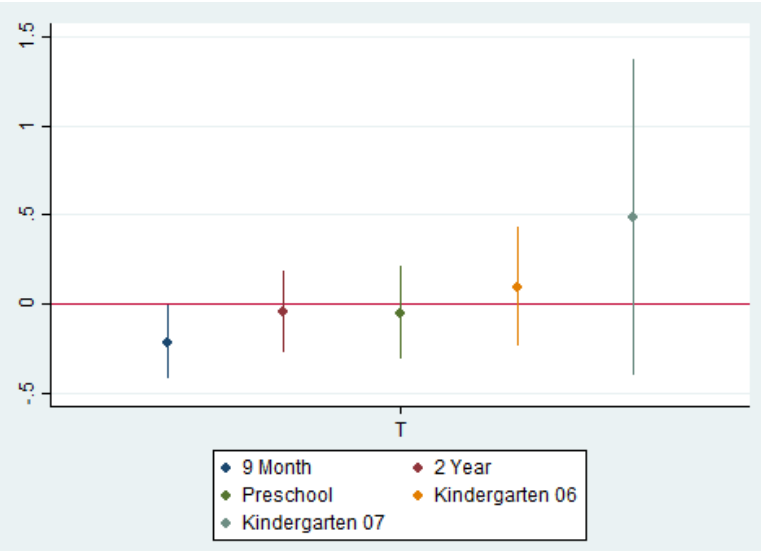

Panel D: Hours worked per week

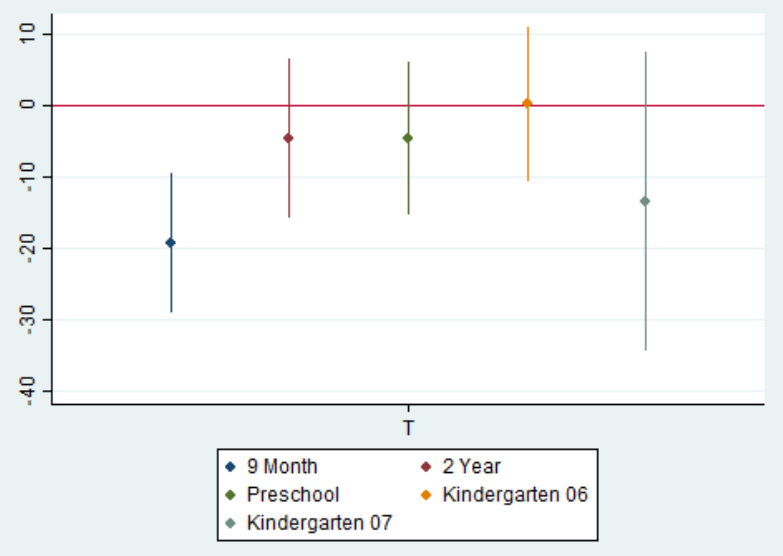

Notes: See notes to Figure 3. For each panel, the point represents a regression coefficient from a linear parametric specification with a $200 \mathrm{~g}$ bandwidth where the outcome is a maternal labor outcome from a different wave. Sample in Panels A-C is as defined in Figure 3. Sample in Panel D is restricted to those who worked a positive number of hours. 
Table 1: Pretreatment Characteristics at the 1200-gram Cutoff, ECLS-B

\begin{tabular}{|c|c|c|c|c|c|c|}
\hline & $\begin{array}{r}(1) \\
\text { Male } \\
\end{array}$ & $\begin{array}{c}(2) \\
\text { Nonwhite } \\
\end{array}$ & $\begin{array}{c}(3) \\
\text { Mom } \\
\text { Unmarried } \\
\end{array}$ & $\begin{array}{c}(4) \\
\text { Apgar } \\
\text { score } \\
\end{array}$ & $\begin{array}{c}(5) \\
\text { First } \\
\text { birth } \\
\end{array}$ & $\begin{array}{c}(6) \\
\text { Winter } \\
\text { Birth } \\
\end{array}$ \\
\hline Dep Var Mean & 0.503 & 0.651 & 0.608 & 7.667 & 0.423 & 0.264 \\
\hline \multicolumn{7}{|c|}{ Flexible Linear Parametric Model - within 200g window } \\
\hline & -0.036 & 0.063 & $0.237^{*}$ & 0.027 & $0.219^{*}$ & 0.009 \\
\hline & $(0.129)$ & $(0.124)$ & $(0.127)$ & $(0.295)$ & $(0.120)$ & $(0.111)$ \\
\hline & [0.987] & [0.973] & [0.283] & [0.995] & [0.309] & [0.995] \\
\hline Observations & 250 & 250 & 250 & 200 & 250 & 250 \\
\hline \multicolumn{7}{|c|}{ Nonparametric - local linear within CCFT window } \\
\hline & -0.006 & 0.140 & 0.247 & -0.007 & $0.339 * *$ & -0.065 \\
\hline & $(0.158)$ & (0.154) & $(0.154)$ & $(0.308)$ & $(0.167)$ & $(0.143)$ \\
\hline Observations & 650 & 650 & 650 & 550 & 650 & 650 \\
\hline Eff obs left & 150 & 150 & 150 & 150 & 100 & 150 \\
\hline Eff obs right & 150 & 100 & 150 & 150 & 100 & 100 \\
\hline BW Local Poly & 241.2 & 206.1 & 231.2 & 275.7 & 159.5 & 204.4 \\
\hline
\end{tabular}

Notes: Data from the ECLS-B. All regressions limited to infants with mother with a high school degree or less and gestational age $<=32$ weeks. Infants born at 32 weeks between 1200 and 1250 grams were dropped from the sample. All sample sizes rounded to nearest 50 as per NCES confidentiality restrictions. Parametric regressions have bootstrapped and non-parametric regressions have robust standard errors in parentheses. ${ }^{* * *} \mathrm{p}<0.01$, ** $\mathrm{p}<0.05,{ }^{*} \mathrm{p}<0.1$. Family-wise $\mathrm{p}$-values that adjust for the number of outcome variables in each family [in brackets] are estimated with the -wyoung- Stata command, using the Westfall and Young (1993) step-down procedure and 10,000 bootstraps, 
Table 2: First Stage and Insurance Coverage

\begin{tabular}{|c|c|c|c|c|c|}
\hline \multicolumn{6}{|c|}{ Panel A: ECLS-B } \\
\hline & (1) & (2) & (3) & (4) & (5) \\
\hline & $\begin{array}{c}(1) \\
\text { SSI/SSDI } \\
\end{array}$ & \multicolumn{4}{|c|}{$\underline{\text { Health Insurance }}$} \\
\hline & $\begin{array}{l}\text { Received } \\
\text { SSI/SSDI } \\
\text { since last } \\
\text { interview }\end{array}$ & $\begin{array}{c}\text { Any health } \\
\text { insurance } \\
\text { coverage }\end{array}$ & $\begin{array}{l}\text { Private } \\
\text { health } \\
\text { insurance }\end{array}$ & $\begin{array}{c}\text { Public } \\
\text { health } \\
\text { insurance }\end{array}$ & $\begin{array}{c}\text { No } \\
\text { coverage at } \\
\text { any time }\end{array}$ \\
\hline Dep Var Mean & $\underline{0.311}$ & $\underline{0.980}$ & $\underline{0.281}$ & $\underline{0.772}$ & $\underline{0.075}$ \\
\hline \multicolumn{6}{|c|}{ Flexible Linear Parametric Model - within 200g } \\
\hline \multicolumn{6}{|l|}{ window } \\
\hline & $(0.118)$ & $(0.048)$ & $(0.113)$ & $(0.116)$ & $(0.061)$ \\
\hline & [0.142] & [0.993] & [0.993] & {$[0.966]$} & [0.447] \\
\hline Observations & 250 & 250 & 250 & 250 & 250 \\
\hline \multicolumn{6}{|c|}{ Nonparametric - local linear within CCT window } \\
\hline & $0.318^{* *}$ & -0.023 & -0.118 & -0.039 & -0.097 \\
\hline & $(0.160)$ & $(0.085)$ & $(0.150)$ & $(0.115)$ & $(0.061)$ \\
\hline Observations & 600 & 650 & 650 & 650 & 650 \\
\hline Eff obs left & 100 & 100 & 100 & 200 & 150 \\
\hline Eff obs right & 100 & 100 & 100 & 200 & 150 \\
\hline BW Local Poly & 192.3 & 178.0 & 182.0 & 363.0 & 232.3 \\
\hline
\end{tabular}

Notes: Data source is ECLS-B 9-month wave, except SSI receipt which is measured at 2-years. All regressions limited to infants with mother with a high school degree or less and gestational age $<=32$ weeks. Infants born at 32 weeks between 1200 and 1250 grams were dropped from the sample.

All sample sizes rounded to nearest 50 as per NCES confidentiality restrictions. Parametric regressions have bootstrapped and non-parametric regressions have robust standard errors in parentheses. ${ }^{* * *} \mathrm{p}<0.01,{ }^{* *} \mathrm{p}<0.05,{ }^{*} \mathrm{p}<0.1$ 
Panel B: Primary and Secondary Expected Payer of Birth, HCUP-SID

\begin{tabular}{|c|c|c|c|c|c|c|c|c|}
\hline & $\begin{array}{c}\text { (1) } \\
\text { Payer 1: } \\
\text { Medicaid }\end{array}$ & $\begin{array}{c}(2) \\
\text { Payer 1: } \\
\text { Private } \\
\text { insurance }\end{array}$ & $\begin{array}{l}\quad \text { (3) } \\
\text { Payer 1: } \\
\text { Self-pay }\end{array}$ & $\begin{array}{l}\text { (4) } \\
\text { Payer 1: } \\
\text { Other }\end{array}$ & $\begin{array}{c}\text { (5) } \\
\text { Payer 2: } \\
\text { Medicaid }\end{array}$ & $\begin{array}{c}(6) \\
\text { Payer 2: } \\
\text { Private } \\
\text { insurance }\end{array}$ & $\begin{array}{c}\text { (7) } \\
\text { Payer 2: } \\
\text { Self-pay }\end{array}$ & $\begin{array}{l}\quad(8) \\
\text { Payer 2: } \\
\text { Other }\end{array}$ \\
\hline $\begin{array}{l}\text { Dep Var } \\
\text { Mean }\end{array}$ & $\underline{0.748}$ & $\underline{0.181}$ & $\underline{0.047}$ & $\underline{0.024}$ & $\underline{0.609}$ & $\underline{0.141}$ & $\underline{0.223}$ & $\underline{0.027}$ \\
\hline \multicolumn{9}{|c|}{ Flexible Linear Parametric Model - within 200g window } \\
\hline & $\begin{array}{c}0.026 \\
(0.069) \\
{[0.992]}\end{array}$ & $\begin{array}{c}-0.014 \\
(0.061) \\
{[0.997]}\end{array}$ & $\begin{array}{l}-0.009 \\
(0.030) \\
{[0.997]}\end{array}$ & $\begin{array}{l}-0.003 \\
(0.023) \\
{[0.997]}\end{array}$ & $\begin{array}{c}0.228 \\
(0.187) \\
{[0.788]}\end{array}$ & $\begin{array}{c}0.021 \\
(0.111) \\
{[0.997]}\end{array}$ & $\begin{array}{l}-0.190 \\
(0.156) \\
{[0.790]}\end{array}$ & $\begin{array}{l}-0.059 \\
(0.089) \\
{[0.948]}\end{array}$ \\
\hline Observations & 683 & 683 & 683 & 683 & 105 & 105 & 105 & 105 \\
\hline \multicolumn{9}{|c|}{ Nonparametric - local linear within CCFT window } \\
\hline & $\begin{array}{c}0.095 \\
(0.091)\end{array}$ & $\begin{array}{l}-0.048 \\
(0.070)\end{array}$ & $\begin{array}{l}-0.007 \\
(0.035)\end{array}$ & $\begin{array}{l}-0.011 \\
(0.031)\end{array}$ & $\begin{array}{l}0.367 * \\
(0.205)\end{array}$ & $\begin{array}{l}-0.021 \\
(0.139)\end{array}$ & $\begin{array}{c}-0.149 \\
(0.147)\end{array}$ & $\begin{array}{l}-0.070 \\
(0.090)\end{array}$ \\
\hline Observations & 2584 & 2584 & 2584 & 2584 & 368 & 368 & 368 & 368 \\
\hline Eff obs left & 309 & 454 & 417 & 363 & 54 & 55 & 87 & 76 \\
\hline Eff obs right & 323 & 422 & 394 & 371 & 59 & 61 & 103 & 92 \\
\hline $\begin{array}{l}\text { BW Local } \\
\text { Poly }\end{array}$ & 185 & 250 & 237 & 216 & 216 & 234 & 376 & 331 \\
\hline
\end{tabular}

Notes: All variables from the HCUP-SID AR 2006-2013, AZ 2006-2007, NC 2006-2010, NM 2012, VT 2012 databases. Sample limited to infants with a person identifier, living in the bottom quartile of the zip code income distribution and gestational age $<=32$ weeks. Infants born at 32 weeks between 1200 and 1250 grams were dropped from the sample. Parametric regressions have bootstrapped and non-parametric regressions have robust standard errors in parentheses. Not all HCUP-SID hospitals report primary or secondary payer. See Appendix Table 7 testing whether the likelihood an infant's primary or secondary payer information is missing varies around the 1200-gram threshold. ${ }^{* * *} \mathrm{p}<0.01,{ }^{* *} \mathrm{p}<0.05,{ }^{*} \mathrm{p}<0.1$. Family-wise $\mathrm{p}$-values that adjust for the number of outcome variables in each family [in brackets] are estimated with the -wyoung- Stata command, using the Westfall and Young (1993) step-down procedure and 10,000 bootstraps, 
Table 3: Infant Mortality-BC-L 2001 Birth Cohort, All States

\begin{tabular}{|c|c|c|c|}
\hline & $\begin{array}{l}\text { (1) } \\
\text { Infant } \\
\text { Death }\end{array}$ & $\begin{array}{c}(2) \\
\text { Post } \\
\text { Neonatal } \\
\text { Death }\end{array}$ & $\begin{array}{c}\text { (3) } \\
\text { Neonatal } \\
\text { Death }\end{array}$ \\
\hline Dep Var Mean & $\underline{0.134}$ & $\underline{0.02}$ & $\underline{0.112}$ \\
\hline \multicolumn{4}{|c|}{ Flexible Linear Parametric Model - within 200g window } \\
\hline & -0.0036 & -0.0011 & -0.002 \\
\hline & $(0.0098)$ & $(0.0057)$ & -0.008 \\
\hline & [0.9217] & [0.9589] & [0.9589] \\
\hline Observations & 9880 & 9880 & 9880 \\
\hline \multicolumn{4}{|c|}{ Nonparametric - local linear within CCFT window } \\
\hline & 0.0107 & 0.0031 & 0.0063 \\
\hline & $(0.014)$ & $(0.0063)$ & -0.0117 \\
\hline Observations & 60319 & 60319 & 60319 \\
\hline Eff obs left & 3484 & 6372 & 3441 \\
\hline Eff obs right & 3629 & 6513 & 3590 \\
\hline BW Local Poly & 146 & 258 & 141 \\
\hline \multicolumn{4}{|c|}{$\begin{array}{l}\text { Notes: All variables from NCHS 2001Birth Cohort Linked Birth - Infant Death Data Files. Sample limited to infants } \\
\text { with mother with a high school degree or less and gestational age }<=32 \text { weeks. Infants born at } 32 \text { weeks between } \\
1200 \text { and } 1250 \text { grams were dropped from the sample. Parametric regressions have bootstrapped and non-parametric } \\
\text { regressions have robust standard errors in parentheses. } * * * p<0.01,{ }^{* *} p<0.05, * p<0.1 \text { Family-wise p-values that } \\
\text { adjust for the number of outcome variables in each family [in brackets] are estimated with the -wyoung- Stata } \\
\text { command, using the Westfall and Young (1993) step-down procedure and } 10,000 \text { bootstraps, }\end{array}$} \\
\hline
\end{tabular}


Table 4: Child Development, Parenting Behaviors at 9-month wave, ECLS-B

\begin{tabular}{|c|c|c|c|c|c|}
\hline \multirow{2}{*}{+2} & $(1)$ & $(2)$ & (3) & (4) & (5) \\
\hline & $\begin{array}{l}\text { Bayley } \\
\text { Mental } \\
\text { T-Score }\end{array}$ & $\begin{array}{l}\text { Bayley } \\
\text { Motor } \\
\text { T-Score }\end{array}$ & $\begin{array}{l}\text { Nursing Child } \\
\text { Assessment } \\
\text { Teaching Scale } \\
\text { - Parent Score }\end{array}$ & $\begin{array}{l}\text { Nursing Child } \\
\text { Assessment } \\
\text { Teaching Scale - } \\
\text { Child Score } \\
\end{array}$ & $\begin{array}{l}\text { Index of Child } \\
\text { Development/Pare } \\
\text { nting Behaviors }\end{array}$ \\
\hline$\underline{\text { Dep Var Mean }}$ & $\underline{43.17}$ & $\underline{45.02}$ & $\underline{33.01}$ & $\underline{14.73}$ & $\underline{0.018}$ \\
\hline \multicolumn{6}{|c|}{ Flexible Linear Parametric Model - within 200g window } \\
\hline & 0.768 & 3.688 & $3.313^{* *}$ & 0.762 & $0.362 * *$ \\
\hline & $(3.510)$ & $(2.890)$ & $(1.532)$ & $(0.833)$ & $(0.180)$ \\
\hline & [0.821] & [0.461] & [0.083] & [0.567] & \\
\hline Observations & 250 & 250 & 200 & 200 & 200 \\
\hline \multicolumn{6}{|c|}{ Nonparametric - local linear within CCT window } \\
\hline & 2.049 & $7.003 * *$ & 3.294 & 0.855 & $0.430 * *$ \\
\hline & $(4.361)$ & $(3.245)$ & $(2.282)$ & $(0.955)$ & $(0.207)$ \\
\hline Observations & 650 & 600 & 500 & 500 & 500 \\
\hline Eff obs left & 100 & 100 & 100 & 100 & 150 \\
\hline Eff obs right & 100 & 100 & 100 & 100 & 150 \\
\hline BW Local Poly & 199.7 & 168.2 & 180.2 & 242.4 & 262.4 \\
\hline
\end{tabular}

Notes: Data source is ECLS-B 9-month wave. All regressions limited to infants with mother with a high school degree or less and gestational age $<=32$ weeks. Infants born at 32 weeks between 1200 and 1250 grams were dropped from the sample.

All sample sizes rounded to nearest 50 as per NCES confidentiality restrictions. Parametric regressions have bootstrapped and non-parametric regressions have robust standard errors in parentheses. ${ }^{* * *} \mathrm{p}<0.01,{ }^{* *} \mathrm{p}<0.05, * \mathrm{p}<0.1$. Family-wise $\mathrm{p}$-values that adjust for the number of outcome variables in each family [in brackets] are estimated with the wyoung stata command, using the Westfall and Young (1993) step-down procedure and 10,000 bootstraps, 
Table 5: Maternal and Paternal Labor Supply, 9-month wave, ECLS-B

Panel A: Maternal Labor Supply

$\begin{array}{cccc}(1) & (2) & (3) & (4) \\ & \text { Mother } & \text { Mother } & \text { Mother's } \\ \text { Mother } & \text { Works } & \text { Works } & \text { Hours paid } \\ \text { Employed } & \text { Full Time } & \text { Part Time } & \text { work/ week }\end{array}$

$\begin{array}{lllll}\text { Dep Var Mean } \quad \underline{0.356} & \underline{0.234} \quad \underline{0.121} \quad \underline{35.54}\end{array}$

Flexible Linear Parametric Model - within 200g window

$\begin{array}{cccc}-0.028 & -0.214^{* *} & 0.187^{* *} & -19.411^{* * *} \\ (0.121) & (0.102) & (0.089) & (4.911) \\ {[0.829]} & {[0.072]} & {[0.064]} & {[0.001]}\end{array}$

$\begin{array}{lllll}\text { Observations } & 250 & 250 & 250 & 100\end{array}$

Nonparametric - local linear within CCT window

$\begin{array}{cccc}-0.039 & -0.234^{*} & 0.145 & -19.292^{* * *} \\ (0.162) & (0.132) & (0.089) & (5.453)\end{array}$

Observations

650

650

$650 \quad 250$

Eff obs left

150

100

$200 \quad 50$

Eff obs right

150

200

50

BW Local Poly

215

199.7

346.2

204.7 


\begin{tabular}{|c|c|c|c|c|}
\hline \multicolumn{5}{|c|}{ Panel B: Paternal Labor Supply } \\
\hline & (1) & (2) & (3) & (4) \\
\hline & $\begin{array}{c}\text { Father } \\
\text { Employed }\end{array}$ & $\begin{array}{c}\text { Father } \\
\text { Works } \\
\text { Full Time }\end{array}$ & $\begin{array}{c}\text { Father } \\
\text { Works } \\
\text { Part Time }\end{array}$ & $\begin{array}{c}\text { Father's } \\
\text { Hours paid } \\
\text { work/ week }\end{array}$ \\
\hline Dep Var Mean & $\underline{0.879}$ & $\underline{0.800}$ & $\underline{0.079}$ & $\underline{44.027}$ \\
\hline \multicolumn{5}{|c|}{ Flexible Linear Parametric Model - within 200g window } \\
\hline & -0.169 & -0.233 & 0.064 & -2.655 \\
\hline & $(0.128)$ & $(0.147)$ & $(0.098)$ & $(5.444)$ \\
\hline & {$[0.525]$} & {$[0.416]$} & {$[0.772]$} & {$[0.772]$} \\
\hline Observations & 150 & 150 & 150 & 150 \\
\hline \multicolumn{5}{|c|}{ Nonparametric - local linear within CCT window } \\
\hline & -0.161 & $-0.348 * *$ & 0.223 & -3.384 \\
\hline & $(0.144)$ & $(0.168)$ & $(0.140)$ & $(6.389)$ \\
\hline Observations & 400 & 400 & 400 & 350 \\
\hline Eff obs left & 100 & 50 & 50 & 100 \\
\hline Eff obs right & 50 & 50 & 50 & 100 \\
\hline BW Local Poly & 203.1 & 192.4 & 160.7 & 287.5 \\
\hline
\end{tabular}

Notes: Data source is ECLS-B 9-month wave. All regressions limited to infants with mother with a high school degree or less and gestational age $<=32$ weeks. Infants born at 32 weeks between 1200 and 1250 grams were dropped from the sample.

All sample sizes rounded to nearest 50 as per NCES confidentiality restrictions. Parametric regressions have bootstrapped and non-parametric regressions have robust standard errors in parentheses. ${ }^{* * *} \mathrm{p}<0.01,{ }^{* *} \mathrm{p}<0.05,{ }^{*} \mathrm{p}<0.1$. Family-wise $\mathrm{p}$-values that adjust for the number of outcome variables in each family [in brackets] are estimated with the -wyoung- Stata command, using the Westfall and Young (1993) step-down procedure and 10,000 bootstraps, 


\section{Table 6: Heterogeneity of Effects by Maternal Childhood AFDC Receipt}

(1)
(2)

Did not receive AFDC
Received AFDC

$0.474^{*}$

$(0.247)$

$(0.141)$

1.588

(5.960)

(4.403)

6.321

(6.010)

(3.426)

6.062*

(3.170)

(1.831)

0.520

(1.656)

(0.986)

$0.628 * *$

(0.294)

0.085

(0.266)

$-0.193$

(0.116)

$0.278 *$

(0.101)

$-21.506^{* * *}$

(8.014)

50
$-17.601^{* * *}$

(6.684)

200

Observations

Notes: Data source is ECLS-B 9-month wave. All regressions limited to infants with mother with a high school degree or less and gestational age $<=32$ weeks. Infants born at 32 weeks between 1200 and 1250 grams were dropped from the sample.

All sample sizes rounded to nearest 50 as per NCES confidentiality restrictions. Parametric regressions have bootstrapped and non-parametric regressions have robust standard errors in parentheses. ${ }^{* * *} \mathrm{p}<0.01,{ }^{* *} \mathrm{p}<0.05,{ }^{*} \mathrm{p}<0.1$ 
Table 7: Robustness to Alternate Specifications, ECLS-B

\begin{tabular}{|c|c|c|c|c|c|c|c|}
\hline & $\begin{array}{c}(1) \\
\text { 200g linear }\end{array}$ & $\begin{array}{c}(2) \\
200 \mathrm{~g} \\
\text { quadratic }\end{array}$ & $\begin{array}{c}\text { (3) } \\
\text { 150g linear }\end{array}$ & $\begin{array}{c}(4) \\
150 g \text { quadratic }\end{array}$ & $\begin{array}{r}(5) \\
\text { CCFT } \\
\end{array}$ & $\begin{array}{c}(6) \\
\text { 200g linear } \\
\text { with covariates }\end{array}$ & $\begin{array}{c}(7) \\
\text { CCFT } \\
\text { with covariates } \\
\end{array}$ \\
\hline SSI & $\begin{array}{c}0.248 * * \\
(0.117)\end{array}$ & $\begin{array}{l}0.322 * \\
(0.175)\end{array}$ & $\begin{array}{c}0.296 * * \\
(0.140)\end{array}$ & $\begin{array}{c}0.230 \\
(0.193)\end{array}$ & $\begin{array}{c}0.318 * * \\
(0.160)\end{array}$ & $\begin{array}{c}0.256^{* *} \\
(0.131)\end{array}$ & $\begin{array}{l}0.280^{*} \\
(0.157)\end{array}$ \\
\hline Bayley Motor & $\begin{array}{c}3.688 \\
(2.831)\end{array}$ & $\begin{array}{l}8.402 * * \\
(3.692)\end{array}$ & $\begin{array}{l}5.589 * \\
(3.168)\end{array}$ & $\begin{array}{l}6.806 * \\
(3.993)\end{array}$ & $\begin{array}{l}7.003^{* *} \\
(3.245)\end{array}$ & $\begin{array}{c}3.092 \\
(3.168)\end{array}$ & $\begin{array}{c}4.724 \\
(3.125)\end{array}$ \\
\hline NCATS Parent & $\begin{array}{c}3.313^{* *} \\
(1.584)\end{array}$ & $\begin{array}{c}3.404 \\
(2.461)\end{array}$ & $\begin{array}{l}3.270 * \\
(1.876)\end{array}$ & $\begin{array}{c}3.942 \\
(2.898)\end{array}$ & $\begin{array}{c}3.294 \\
(2.282)\end{array}$ & $\begin{array}{l}3.003 * \\
(1.703)\end{array}$ & $\begin{array}{l}3.763 * \\
(2.030)\end{array}$ \\
\hline Child Dev/Parenting Index & $\begin{array}{l}0.362 * \\
(0.185)\end{array}$ & $\begin{array}{l}0.495 * \\
(0.286)\end{array}$ & $\begin{array}{c}0.433 * * \\
(0.220)\end{array}$ & $\begin{array}{l}0.560 * \\
(0.293)\end{array}$ & $\begin{array}{c}0.430 * * \\
(0.207)\end{array}$ & $\begin{array}{c}0.198 \\
(0.223)\end{array}$ & $\begin{array}{c}0.238 \\
(0.211)\end{array}$ \\
\hline Mom works & $\begin{array}{l}-0.028 \\
(0.124)\end{array}$ & $\begin{array}{l}-0.050 \\
(0.181)\end{array}$ & $\begin{array}{l}-0.150 \\
(0.147)\end{array}$ & $\begin{array}{c}0.220 \\
(0.205)\end{array}$ & $\begin{array}{l}-0.039 \\
(0.162)\end{array}$ & $\begin{array}{l}-0.111 \\
(0.145)\end{array}$ & $\begin{array}{l}-0.105 \\
(0.164)\end{array}$ \\
\hline Mom works FT & $\begin{array}{c}-0.214^{* *} \\
(0.100)\end{array}$ & $\begin{array}{l}-0.199 \\
(0.144)\end{array}$ & $\begin{array}{c}-0.276^{* *} \\
(0.119)\end{array}$ & $\begin{array}{l}-0.069 \\
(0.166)\end{array}$ & $\begin{array}{l}-0.234 * \\
(0.132)\end{array}$ & $\begin{array}{c}-0.283^{* *} \\
(0.126)\end{array}$ & $\begin{array}{l}-0.254 * \\
(0.146)\end{array}$ \\
\hline Mom works PT & $\begin{array}{c}0.187 * * \\
(0.090)\end{array}$ & $\begin{array}{c}0.149 \\
(0.134)\end{array}$ & $\begin{array}{c}0.126 \\
(0.105)\end{array}$ & $\begin{array}{l}0.289 * \\
(0.155)\end{array}$ & $\begin{array}{c}0.145 \\
(0.089)\end{array}$ & $\begin{array}{l}0.172 * \\
(0.095)\end{array}$ & $\begin{array}{c}0.183 \\
(0.118)\end{array}$ \\
\hline Mother's hours paid work & $\begin{array}{c}-19.411^{* * *} \\
(4.898)\end{array}$ & $\begin{array}{c}-12.863^{*} \\
(6.895)\end{array}$ & $\begin{array}{c}-16.965^{* * *} \\
(5.206)\end{array}$ & $\begin{array}{c}-16.665^{* *} \\
(7.768)\end{array}$ & $\begin{array}{c}-19.292^{* * * *} \\
(5.453)\end{array}$ & $\begin{array}{c}-16.087 * * * \\
(5.471)\end{array}$ & $\begin{array}{c}-16.787 * * * \\
(5.118)\end{array}$ \\
\hline
\end{tabular}


Table 8: Robustness to Alternative Samples and Falsification Tests, ECLS-B

\begin{tabular}{|c|c|c|c|c|c|c|}
\hline & Baseline & $\begin{array}{c}(2) \\
\text { Only } \\
\text { Ounce } \\
\text { Heaps } \\
\end{array}$ & $\begin{array}{c}\text { (3) } \\
\text { Without } \\
\text { NY } \\
\end{array}$ & $1100 \mathrm{~g}$ & $1300 \mathrm{~g}$ & $\begin{array}{l}\text { (6) } \\
\text { Mothers with } \\
\text { College }\end{array}$ \\
\hline SSI - 200g & $\begin{array}{c}0.248 * * \\
(0.121)\end{array}$ & $\begin{array}{c}0.301^{* *} \\
(0.135)\end{array}$ & $\begin{array}{c}0.231 * * \\
(0.117)\end{array}$ & $\begin{array}{c}-0.141 \\
(0.127)\end{array}$ & $\begin{array}{c}-0.124 \\
(0.110)\end{array}$ & $\begin{array}{c}0.023 \\
(0.086)\end{array}$ \\
\hline SSI - CCFT & $\begin{array}{c}0.318 * * \\
(0.160)\end{array}$ & $\begin{array}{c}0.425^{* *} \\
(0.178)\end{array}$ & $\begin{array}{c}0.300 * * \\
(0.142)\end{array}$ & $\begin{array}{c}0.059 \\
(0.173)\end{array}$ & $\begin{array}{c}-0.247^{*} \\
(0.141)\end{array}$ & $\begin{array}{l}-0.155 \\
(0.115)\end{array}$ \\
\hline Bayley Motor - 200g & $\begin{array}{c}3.688 \\
(2.890)\end{array}$ & $\begin{array}{c}5.476 \\
(3.820)\end{array}$ & $\begin{array}{c}2.697 \\
(3.068)\end{array}$ & $\begin{array}{c}1.258 \\
(2.726)\end{array}$ & $\begin{array}{l}-3.943 \\
(3.008)\end{array}$ & $\begin{array}{c}-1.339 \\
(3.303)\end{array}$ \\
\hline Bayley Motor - CCFT & $\begin{array}{c}7.003 * * \\
(3.245)\end{array}$ & $\begin{array}{c}8.014 * * \\
(3.966)\end{array}$ & $\begin{array}{l}6.332 * \\
(3.479)\end{array}$ & $\begin{array}{c}0.931 \\
(4.066)\end{array}$ & $\begin{array}{l}-4.973 \\
(3.187)\end{array}$ & $\begin{array}{c}0.231 \\
(4.578)\end{array}$ \\
\hline NCATS parent - 200g & $\begin{array}{c}3.313 * * \\
(1.498)\end{array}$ & $\begin{array}{c}2.921 \\
(1.926)\end{array}$ & $\begin{array}{c}3.233 * * \\
(1.595)\end{array}$ & $\begin{array}{l}-1.245 \\
(1.443)\end{array}$ & $\begin{array}{l}-1.652 \\
(1.327)\end{array}$ & $\begin{array}{c}-2.063 \\
(1.549)\end{array}$ \\
\hline NCATS parent - CCFT & $\begin{array}{c}3.294 \\
(2.282)\end{array}$ & $\begin{array}{c}2.343 \\
(2.582)\end{array}$ & $\begin{array}{c}2.650 \\
(2.324)\end{array}$ & $\begin{array}{c}-1.477 \\
(1.751)\end{array}$ & $\begin{array}{l}-2.494 \\
(1.637)\end{array}$ & $\begin{array}{l}-1.711 \\
(2.382)\end{array}$ \\
\hline Development Index - 200g & $\begin{array}{l}0.362 * \\
(0.189)\end{array}$ & $\begin{array}{c}0.299 \\
(0.235)\end{array}$ & $\begin{array}{c}0.290 \\
(0.193)\end{array}$ & $\begin{array}{c}-0.012 \\
(0.167)\end{array}$ & $\begin{array}{c}-0.370 * * \\
(0.157)\end{array}$ & $\begin{array}{c}-0.231 \\
(0.185)\end{array}$ \\
\hline Development Index - CCFT & $\begin{array}{c}0.430 * * \\
(0.207)\end{array}$ & $\begin{array}{c}0.333 \\
(0.272)\end{array}$ & $\begin{array}{c}0.329 \\
(0.211)\end{array}$ & $\begin{array}{l}-0.160 \\
(0.214)\end{array}$ & $\begin{array}{c}-0.441^{* *} \\
(0.184)\end{array}$ & $\begin{array}{c}-0.326 \\
(0.253)\end{array}$ \\
\hline Mom works - 200g & $\begin{array}{l}-0.028 \\
(0.124)\end{array}$ & $\begin{array}{c}-0.077 \\
(0.154)\end{array}$ & $\begin{array}{l}-0.007 \\
(0.128)\end{array}$ & $\begin{array}{c}0.257 * * \\
(0.126)\end{array}$ & $\begin{array}{c}0.100 \\
(0.127)\end{array}$ & $\begin{array}{c}-0.131 \\
(0.155)\end{array}$ \\
\hline Mom works - CCFT & $\begin{array}{l}-0.039 \\
(0.162)\end{array}$ & $\begin{array}{c}-0.076 \\
(0.153)\end{array}$ & $\begin{array}{l}-0.024 \\
(0.170)\end{array}$ & $\begin{array}{c}0.336 * * \\
(0.148)\end{array}$ & $\begin{array}{c}0.039 \\
(0.143)\end{array}$ & $\begin{array}{l}-0.210 \\
(0.227)\end{array}$ \\
\hline
\end{tabular}




\begin{tabular}{|c|c|c|c|c|c|c|}
\hline Mom works FT - 200g & $\begin{array}{c}-0.214^{* *} \\
(0.105)\end{array}$ & $\begin{array}{l}-0.235^{*} \\
(0.125)\end{array}$ & $\begin{array}{c}-0.219 * * \\
(0.107)\end{array}$ & $\begin{array}{l}0.291^{* * *} \\
(0.112)\end{array}$ & $\begin{array}{c}0.115 \\
(0.121)\end{array}$ & $\begin{array}{l}-0.052 \\
(0.156)\end{array}$ \\
\hline Mom works FT - CCFT & $\begin{array}{l}-0.234^{*} \\
(0.132)\end{array}$ & $\begin{array}{l}-0.193 \\
(0.154)\end{array}$ & $\begin{array}{l}-0.241 * \\
(0.140)\end{array}$ & $\begin{array}{l}0.306^{* *} \\
(0.152)\end{array}$ & $\begin{array}{c}0.091 \\
(0.139)\end{array}$ & $\begin{array}{l}-0.040 \\
(0.218)\end{array}$ \\
\hline Mom works PT - 200g & $\begin{array}{l}0.187 * * \\
(0.090)\end{array}$ & $\begin{array}{c}0.159 \\
(0.118)\end{array}$ & $\begin{array}{l}0.212^{* *} \\
(0.099)\end{array}$ & $\begin{array}{l}-0.034 \\
(0.085)\end{array}$ & $\begin{array}{l}-0.014 \\
(0.068)\end{array}$ & $\begin{array}{l}-0.079 \\
(0.115)\end{array}$ \\
\hline Mom works PT - CCFT & $\begin{array}{c}0.145 \\
(0.089)\end{array}$ & $\begin{array}{c}0.162 \\
(0.146)\end{array}$ & $\begin{array}{l}0.203^{*} \\
(0.112)\end{array}$ & $\begin{array}{c}0.023 \\
(0.101)\end{array}$ & $\begin{array}{l}-0.058 \\
(0.077)\end{array}$ & $\begin{array}{l}-0.219 \\
(0.150)\end{array}$ \\
\hline $\begin{array}{l}\text { Mother's hours paid work - } \\
200 \mathrm{~g}\end{array}$ & $\begin{array}{c}-19.411^{* * *} \\
(5.0963)\end{array}$ & $\begin{array}{l}-19.815^{* * *} \\
\quad(6.228)\end{array}$ & $\begin{array}{l}-20.381^{* * *} \\
(5.130)\end{array}$ & $\begin{array}{c}11.245^{* *} \\
(5.615)\end{array}$ & $\begin{array}{c}6.100 \\
(4.121)\end{array}$ & $\begin{array}{c}2.279 \\
(5.302)\end{array}$ \\
\hline $\begin{array}{l}\text { Mother's hours paid work - } \\
\text { CCFT }\end{array}$ & $\begin{array}{c}-19.292 * * * \\
(5.453) \\
\end{array}$ & $\begin{array}{c}-19.303^{* *} \\
(7.627) \\
\end{array}$ & $\begin{array}{c}-18.904 * * * \\
(5.768) \\
\end{array}$ & $\begin{array}{c}7.722 \\
(7.881) \\
\end{array}$ & $\begin{array}{l}7.751^{*} \\
(4.598) \\
\end{array}$ & $\begin{array}{c}2.580 \\
(6.264) \\
\end{array}$ \\
\hline
\end{tabular}

